\title{
The role of complementary feeding in India's enigma of high child malnutrition rates: Findings from a comprehensive national study
}

Ivica Petrikova ( $\sim$ ivica.petrikova@rhul.ac.uk)

Royal Holloway University of London

\section{Research Article}

Keywords: Child malnutrition, India, infant and young child feeding, animal-source foods, ICDS, poultry ownership

Posted Date: September 16th, 2020

DOI: https://doi.org/10.21203/rs.3.rs-78314/v1

License: (c) (i) This work is licensed under a Creative Commons Attribution 4.0 International License.

Read Full License

Version of Record: A version of this preprint was published at Food Security on September 16th, 2020. See the published version at https://doi.org/10.1007/s12571-021-01202-7. 


\title{
The role of complementary feeding in India's enigma of high child malnutrition rates: Findings from a comprehensive national study
}

\author{
Ivica Petrikova
}

\begin{abstract}
Relative to its economic growth and poverty levels, Indian children suffer from higher levels of malnutrition than children in most other low- or lower-middle-income countries. The current Covid19 pandemic is likely to further exacerbate the situation. Research presented in this article has examined the effects of infant and young child feeding practices on the rates of stunting, underweight, wasting, and anaemia amongst Indian children and concluded that feeding children between 6 and 23 months old (semi)solid food of sufficient variety, and particularly animal-source foods, has a significant positive effect on their nutritional outcomes. The study further assessed the effects of the Integrated Child Development Services and district-level livestock ownership on the helpful feeding practices and found that the Integrated Child Development Services encouraged beneficial dietary behaviour amongst children but did not improve their nutritional outcomes. In contract, district-level poultry ownership appeared to have both augmented the beneficial feeding practices and improved children's nutritional outcomes.
\end{abstract}

\section{Keywords}

Child malnutrition; India; infant and young child feeding; animal-source foods; ICDS; poultry ownership

\section{Introduction}

On the 2019 Global Hunger Index (GHI), where three of four composite indicators relate to child-malnourishment rates, India ranked $102^{\text {nd }}$ out of 117 countries, well below many economically poorer countries including Myanmar (69), Nepal (73), and Bangladesh (88). India's inordinately high incidence of child malnourishment relative to its income level has been dubbed the 'South Asian' enigma (Ramalingaswami et al. 1997). Some researchers have disputed this label with the contention that South Asian people may be genetically shorter and/or thinner than people of other ethnic origins (e.g. Hruschka and Hadley 2016, Yajnik et al. 2003). However, multiple studies have shown affluent Indian children to follow statistically indistinguishable growth patterns from well-nourished children elsewhere in the world, particularly in young age (e.g. Bhandari et al. 2002). Furthermore, India's 
neighbouring countries have had more success in reducing child malnourishment rates in populations ethnically akin to India's (Headey et al. 2015). Although India has also reduced the rates of child malnutrition in the past few decades, with still almost 40 per cent of children under five years old stunted (too short for age) and more than 20 per cent wasted (too light for height), the country has clearly a long way to go to ensure food and nutrition security for all its children. Given the vastly negative health, educational, and economic implications of child malnutrition for both the individuals affected and their communities (Dewey and Begum 2011), combined with the negative effects of Covid-19 pandemic on children in India, investigations into factors underlying India's persistently high rates of child malnutrition are imperative. Infant and young child feeding (IYCF) has been identified, alongside demographic, socio-economic, and water, sanitation, and hygiene (WASH) factors, as a key determinant of children's nutritional outcomes during their first 1,000 days, which are particularly crucial for nutritional and health outcomes later in life. This article contributes to existing knowledge on this topic with findings from a comprehensive, nationally representative study of the determinants of malnourishment rates in Indian children between 6 and 23 months old, with a focus on their feeding practices.

Vis-à-vis IYCF, the World Health Organisation (WHO) recommends that all children are breastfed within the first hour of life and breastfed exclusively, without additional food or liquids, until they are 6 months old. Thereafter, it advises that children begin receiving solid, semi solid, or mushy foods in addition to breastmilk and that the complementary feeds are sufficiently frequent and diverse (WHO's Minimum Acceptable Diet, explained in more detail later). There is a wealth of empirical research from lower-income settings, including India, on the links between infant and young child feeding and children's health and nutritional outcomes. Regarding breastfeeding, many studies discovered children breastfed promptly after birth (and thus ingesting colostrum - 'first milk' - rich in nutrients and antibodies) to be healthier than those who were not (Bhutia 2014, Jeyakumar et al. 2019, Mishra et al. 2014, Roche et al. 2016, Teshome et al. 2009). Similarly, giving infants pre-lacteal feeds - i.e. non-human milk, water, honey or other liquids before breast milk - was found in some studies to harm infants' health (Amsalu and Tigabu 2008, Bhutia 2014, Gupta et al. 2015, Mishra et al. 2014, Teshome et al. 2009). Both not exclusively breastfeeding children for their first 6 months of life and bottle-feeding them have also been linked with higher undernourishment rates amongst infants in some studies (Amsalu and Tigabut 2008, Bharati et al. 2018, Mishra et al. 2014). However, Teshome et al. (2009) found Ethiopian children breastfed after one year of age to suffer from higher rates of stunting than non-breastfed children. The authors opined that this was not because of the continued ingestion of breast milk but due to a lower nutrient content of the children's complementary feeds. 
In relation with complementary feeding, many studies discovered 'late weaning' - i.e. initiation of complementary feeding after 6 months of age - to be associated with higher rates of stunting and other malnutrition outcomes amongst children (Bhutia 2014, Bukusuba et al. 2017, Roche et al. 2016, Shamim et al. 2006, Teshome et al., 2009). Petrikova (2018), in a comparative analysis of India and Ethiopia, noted the much higher rate of late weaning in India as one potential cause of higher malnutrition prevalence amongst Indian than amongst Ethiopian children. There has been some disagreement in the studies about the ideal age to start the supplementation, however. Whilst many consider 6 months the right age, in line with the WHO recommendations, others see the ideal starting period to be between 4 to 6 months (Shamim et al. 2006, Teshome et al. 2009, Vyas et al. 2014) or even prior to 4 months (Kumar et al. 2006, Padmadas et al. 2002). Yet other studies strongly disagree with the latter proposition, positing that early ${ }^{1}$ initiation of complementary feeding can harm children's nutritional outcomes (Bhutia 2014, Gupta et al. 2015, Shamim et al. 2006). In terms of the frequency and quality of complementary feeding, cereal-based weaning was found to be correlated with higher rates of stunting (Teshome et al. 2009) whilst the consumption of animal-source foods (Bukusuba et al. 2017, Krasevec et al. 2016) and iron-rich foods (Roche et al. 2016) with lower stunting rates. However, Mishra et al. (2014) discovered no significant link between the frequency of complementary feeding and incidence of malnutrition.

Looking at factors other than IYCF that affect children's nutritional outcomes, individual-level variables that raise the risk of malnourishment include being male (Gupta et al. 2015, Jeyakumar et al. 2019, Roche et al. 2016), having a low birth weight (Gupta et al. 2015, Jeyakumar et al. 2019), having a short birth interval with a preceding sibling (Gupta et al. 2015), and not being fully immunised (Gupta et al. 2015, Jeyakumar et al. 2019, Mishra et al. 2014). Older (Padmadas et al. 2002), more nourished mothers (Bharati et al. 2018, Bhutia 2014) with fewer children (Amsalu and Tigabu 2008) are less likely to have malnourished children. From socio-economic determinants, the most commonly cited is the importance of mother's - and to a lesser degree father's - education (e.g. Amasalu and Tigabu 2008, Bharati et al. 2018, Jayant et al. 2010, Mishra et al. 2014). Wealthier households have also been found to have fewer undernourished children (Amasalu and Tigabu 2008, Bharati et al. 2018, Bhutia 2014, Teshome et al. 2009). Other variables put forward as potentially important have included class (Jayant et al. 2010), caste (Kumar et al. 2006), and rural/urban zone of residence (Bhutia 2014). Finally, WASH factors have been increasingly also linked with children's nutritional outcomes, with Meshram et al. (2018) finding Indian children in households with private toilets to be significantly less stunted and underweight than other children. An earlier study by Spears et al. (2013) even concluded

\footnotetext{
1 Prior to six months of age
} 
that inter-district differences in open-defecation rates within India could account for up to 55 per cent of variation in their child stunting rates and thus explain a large part of the Indian enigma.

Nevertheless, a significant part of the conundrum that India continues to experience very high rates of child malnutrition despite high economic growth and significant poverty reduction in recent decades remains unanswered. The study presented here aims to enlighten the puzzle further with a comprehensive analysis of the effects of IYCF on Indian children's nutritional outcomes using nationally representative data from the National Family Health Survey (NFHS) IV. Finding robust evidence that feeding Indian toddlers a sufficiently varied diet, and particularly animal-source foods, significantly reduces their risk of being malnourished, the study further examines whether receiving help from the Integrated Child Development Services (ICDS) and owning livestock can help ensure that children consume the nutritionally beneficial foods. The motivation for scrutinising the ICDS comes from the fact that the programme is the country's largest one aimed at improving children's health and that past studies suggested that it may have a positive effect on children's nutritional outcomes (Kumar et al. 2006). Livestock ownership, meanwhile, could be plausibly linked with greater consumption of animal-source foods by children even among poor families given the generally high market prices of these items (Headey et al. 2018). The study finds both measures to be at least partially helpful - with children receiving ICDS benefits and living in districts with a greater ownership of poultry to be consuming more varied diets and more animal-source foods than their counterparts.

\section{Methodology}

\subsection{Data and models}

The study analyses data from more than 57,000 Indian children between 6 and 23 months of age gathered by NFHS IV, a nationally representative Indian household survey, in 2015-16. The lower cut-off age of 6 months was selected due to the WHO recommendation for children from that age onwards to be weaned; i.e. to receive solid, semi-solid or mushy foods as a supplement to breast milk (WHO 2005). The upper cut-off point was selected in view of the first two years of children's lives being the most crucial to ensuring good nutritional outcomes in later life (UNICEF 2017).

The scheme of the main empirical model examined is the following:

Child's nutritional outcome $=$ child's IYCF + child's/household's demographic characteristics + household's socio-economic characteristics + WASH + communal characteristics 
The models are estimated using Probit regressions, as all dependent variables are binary, with robust standard errors clustered by Indian state. As a robustness check, the models are also estimated using multilevel logit regressions.

Findings on the links between IYCF and children's nutritional outcomes are interrogated further by examining whether receiving help from the ICDS and/or owning livestock may be helpful in ensuring beneficial feeding practices and improving nutritional outcomes. In assessing the impact of the ICDS, I use Propensity Score Matching (PSM), a quasi-experimental method that is based on the construction of a synthetic suitable control group to the 'treated' children (who received support from the programme) from 'untreated' children on the basis of observable characteristics (e.g. Ravallion 2001). The output indicators of the 'constructed' control group are then subtracted from those of the treated group to determine the size and significance of the treatment's impact. The specific type of matching used is the five-nearest-neighbours one, with the nearest-neighbour method used as a robustness check.

Regarding livestock ownership, I first matched NFHS IV data with data available from the Indian Human Development Survey II (2011-2012) at the level of districts (640 districts in total) to import into the NFHS IV dataset information about the percentage of livestock-owning households in each district. I then analyse the impact of livestock ownership through a suite of Probit regressions analogous to those used to estimate the original models.

\subsection{Variables}

As dependent variables, the study examines four key child malnutrition measures - stunting (too short for age), underweight (too light for age), wasting (too light for height), and suffering from anaemia (lower than normal red-blood-cell count). All four measures can be brought about by deficient feeding but stunting is generally reflective of longer-term nutritional deprivation whilst wasting of more short-term deprivation. Underweight can be a result of either stunting or wasting whereas anaemia may be caused by iron-deficient diet, alongside frequent diarrhoea and/or intestinal parasites (WHO 2010).

IYCF factors, the key independent variables investigated, include whether a child is still breastfed, whether s/he is weaned (aka, received any non-liquid food in the previous 24 hours), and whether her/his diet in the last 24 hours complied with the WHO's Minimum Acceptable Diet (MAD) guidelines regarding dietary diversity and frequency of complementary feeding. The WHO (2008, 2018) defines minimum dietary diversity as consuming every 24 hours foods from at least four food groups out of the following seven: (1) grains, roots, and tubers; (2) legumes and nuts; (3) dairy products (e.g. yogurt, cheese); (4) flesh foods (meat, fish, poultry, and organ meats); (5) eggs; (6) 
vitamin-A rich fruits and vegetables; and (7) other fruits and vegetables. The minimum meal frequency is defined differently for breastfed and non-breastfed children - with breastfed 6-to-8-month-old children needing two and 9-to-23-month-old children three non-milk feeds per day, whilst nonbreastfed children between 6 and 23 months of age needing four feeds (along with at least two milk feeds). Following the WHO guidelines on toddler feeding - breastfeeding along with complementary feeding of sufficient diversity and frequency - is generally expected to reduce the incidence of all four measures of child malnutrition. I investigate the effects of the different food groups in separate models as well, with a particular focus on animal-source foods - dairy, flash foods, and eggs, given existing findings suggesting a link between their consumption and reduced stunting (e.g. Krasevec et al. 2016).

The models employed control for a range of additional child characteristics: the child's gender and age group, whether s/he was of a small birth size (a subjective measure as the exact birth weight could not be recalled by the majority of caregivers), whether s/he was born prematurely (preterm), and the child's birth order and birth interval with preceding sibling. Further control variables measured at the child level include a question about having received any pre-lacteal feed, been breastfed within one hour of birth, and suffered from diarrhoea in the preceding two weeks.

Household-level variables included in the models are mother's age at the child's birth, her nutritional state, and her education level, the household size, whether the household is of scheduled caste/scheduled tribe background, and if it is female-headed. Further, the model controls for the household's wealth group (quintile) and the number of children under five years old in the household. The sanitation measures controlled for are whether household members have access to a private improved toilet ${ }^{2}$ and district-level prevalence of private improved toilets. Finally, communal-level variables include whether the area is urban or rural and India's region (Southern, Northeastern, Northern, Eastern, Central, and Western).

In interrogating the effects of ICDS and owning livestock on children's IYCF and nutritional outcomes, I utilise seven further variables. In terms of ICDS, I consider whether receiving weekly food support from the programme, monthly health check-ups, monthly weighing/measuring, and regularly attending an ICDS pre-school have affected children's complementary feeding and through that pathway their nutritional outcomes. I do the same for livestock ownership, by investigating links between district prevalence of general livestock, cow, and poultry ownership and children's IYCF and nutritional outcomes. It would have been helpful to also examine the link between household-level

\footnotetext{
2 "Improved toilets" hygienically separate human excreta from human contact: https://www.who.int/water_sanitation_health/monitoring/jmp2012/key_terms/en/
} 
livestock ownership and children's nutrition; this was not possible, however, due to the unavailability of such data in the NFHS IV.

\subsection{Summary statistics}

Table 1 displays the summary statistics of all the variables used. The first part of the table shows that the proportions of 6-to-23-month-old Indian children suffering from deficient nutritional outcomes in 2015-16 were high: 36 per cent were stunted, 32 per cent underweight, 23 per cent wasted, and 57 per cent anaemic.

Table 1. Descriptive statistics of the variables used

\begin{tabular}{|c|c|c|c|c|c|}
\hline \multirow{2}{*}{$\begin{array}{l}\text { Variable } \\
\text { Nutritional outcomes }\end{array}$} & \multirow[t]{2}{*}{$\mathbf{N}$} & Mean & \multirow[t]{2}{*}{ Std. Dev. Min } & \multicolumn{2}{|c|}{ Max } \\
\hline & & & & & \\
\hline Stunted & 57,021 & 0.36 & 0.48 & 0 & 1 \\
\hline Underweight & 57,021 & 0.32 & 0.47 & 0 & 1 \\
\hline Wasted & 57,021 & 0.23 & 0.42 & 0 & 1 \\
\hline Anaemic & 56,811 & 0.57 & 0.50 & 0 & 1 \\
\hline \multicolumn{6}{|l|}{ Infant \& young child feeding } \\
\hline Weaned (eating non-liquid food) & 57,021 & 0.77 & 0.42 & 0 & 1 \\
\hline Minimum dietary diversity & 57,021 & 0.21 & 0.41 & 0 & 1 \\
\hline Minimum dietary frequency & 57,021 & 0.32 & 0.47 & 0 & 1 \\
\hline Breastfeeding & 57,021 & 0.88 & 0.33 & 0 & 1 \\
\hline \multicolumn{6}{|l|}{ Consumed in last 24 hours } \\
\hline Grains, roots, and tubers & 57,021 & 0.71 & 0.45 & 0 & 1 \\
\hline Legumes and nuts & 57,021 & 0.14 & 0.35 & 0 & 1 \\
\hline Dairy products & 57,021 & 0.26 & 0.44 & 0 & 1 \\
\hline Flesh foods & 57,021 & 0.11 & 0.32 & 0 & 1 \\
\hline Eggs & 57,021 & 0.14 & 0.35 & 0 & 1 \\
\hline Vit.A-rich fruits and vegetables & 57,021 & 0.42 & 0.49 & 0 & 1 \\
\hline Other fruits and vegetables & 57,021 & 0.35 & 0.48 & 0 & 1 \\
\hline Any animal-source foods & 57,021 & 0.36 & 0.48 & 0 & 1 \\
\hline \multicolumn{6}{|l|}{ Child characteristics } \\
\hline Female child & 57,021 & 0.48 & 0.50 & 0 & 1 \\
\hline \multicolumn{6}{|l|}{ Age bracket } \\
\hline 6-11 months & 57,021 & 0.35 & & & \\
\hline $12-17$ months & 57,021 & 0.34 & & & \\
\hline 18-23 months & 57,021 & 0.32 & & & \\
\hline Small birth size & 57,021 & 0.12 & 0.32 & 0 & 1 \\
\hline Preterm & 57,021 & 0.06 & 0.24 & 0 & 1 \\
\hline Any prelacteal feed & 57,021 & 0.21 & 0.41 & 0 & 1 \\
\hline Breastfed within 1 hour of birth & 57,021 & 0.70 & 0.46 & 0 & 1 \\
\hline Had diarrhoea in the last 2 weeks & 57,021 & 0.15 & 0.35 & 0 & 1 \\
\hline Birth order & 57,021 & 2.28 & 1.45 & 1 & 15 \\
\hline Birth interval & 57,021 & 24.78 & 26.04 & 0 & 275 \\
\hline \multicolumn{6}{|l|}{ Household characteristics } \\
\hline Mother's age at birth & 57,021 & 25.43 & 4.87 & 14 & 49 \\
\hline Mother undernourished & 57,021 & 0.20 & 0.40 & 0 & 1 \\
\hline Mother's education & 57,021 & & & & \\
\hline None & & 0.29 & & & \\
\hline Primary & & 0.14 & & & \\
\hline Secondary & & 0.47 & & & \\
\hline Higher & & 0.10 & & & \\
\hline $\mathrm{HH}$ size & 57,021 & 6.46 & 2.86 & 2 & 41 \\
\hline Female head of $\mathrm{HH}$ & 57,021 & 0.12 & 0.33 & 0 & 1 \\
\hline No. of children under 5 & 57,021 & 1.80 & 0.87 & 0 & 9 \\
\hline Scheduled caste/tribe & 57,021 & 0.41 & 0.49 & 0 & 1 \\
\hline Wealth quintile & 57,021 & & & & \\
\hline Lowest & & 0.26 & & & \\
\hline Lower middle & & 0.23 & & & \\
\hline Middle & & 0.20 & & & \\
\hline Upper middle & & 0.17 & & & \\
\hline Highest & & 0.14 & & & \\
\hline
\end{tabular}


Table 1. (continued) Descriptive statistics of the variables used

\begin{tabular}{|c|c|c|c|c|c|}
\hline Sanitation & & & & & \\
\hline Private improved toilet & 57,021 & 0.42 & 0.49 & 0 & 1 \\
\hline District toilet prevalence & 57,021 & 0.41 & 0.22 & 0.04 & 1 \\
\hline \multicolumn{6}{|l|}{ Communal characteristics } \\
\hline Urban & 57,021 & 0.24 & 0.43 & 0 & 1 \\
\hline Region & 57,021 & & & & \\
\hline Southern & & 0.10 & & & \\
\hline Northeastern & & 0.14 & & & \\
\hline Eastern & & 0.22 & & & \\
\hline Northern & & 0.16 & & & \\
\hline Central & & 0.31 & & & \\
\hline Western & & 0.07 & & & \\
\hline \multicolumn{6}{|l|}{ Help from ICDS } \\
\hline Weekly (at least) food & 57,021 & 0.53 & 0.50 & 0 & 1 \\
\hline Monthly (at least) health checkup & 57,021 & 0.31 & 0.46 & 0 & 1 \\
\hline Monthly (at least) weighing/measuring & 57,021 & 0.27 & 0.44 & 0 & 1 \\
\hline Regular preschool attendance & 57,021 & 0.16 & 0.36 & 0 & 1 \\
\hline \multicolumn{6}{|l|}{ Livestock ownership - district level } \\
\hline District livestock ownership & 56,785 & 0.43 & 0.22 & 0 & 0.92 \\
\hline District cow ownership & 56,785 & 0.19 & 0.14 & 0 & 0.68 \\
\hline District poultry ownership & 56,785 & 0.09 & 0.12 & 0 & 0.65 \\
\hline
\end{tabular}

Looking at children's dietary habits, the rates of breastfeeding were high, with 88 per cent of the sample children breastfed. Whilst the rate declined with children's age, almost 80 per cent of children between 18 and 23 months of age were still breastfed. Meanwhile, 77 per cent of the children examined received some non-liquid food in the 24 hours prior to the survey, with the proportion higher in higher age categories: 6-11 months - 59 per cent, 12-17 months - 85 per cent, and 18-23 months - 90 per cent. The diet of only 32 per cent of the children complied with the WHO guidelines on minimum feeding frequency, however, and of only 21 per cent with guidelines on minimum dietary diversity. The most commonly consumed food groups were grains, roots, and tubers, followed by Vitamin-A rich fruits and vegetables and other fruits and vegetables. 36 per cent of the sampled children were fed some animal-source foods in the day before the survey.

Turning to summary statistics of the control variables, slightly fewer than half of the sample were female children. Twelve per cent were deemed to have been of small birth size by their parents and 6 per cent had been born prematurely. Twenty one per cent had been given a pre-lacteal feed and 70 per cent had been breastfed within one hour of birth. Fifteen per cent had suffered from diarrhoea in the two weeks prior to the survey. The average child in the survey had been born second in the family, with the older sibling approximately two years older.

The average age of the child's mother at birth was 25 years, with most mothers having completed at least a secondary-level education. Thirty per cent of the mothers had received no education, however. Forty one percent of households declared to be of scheduled caste or scheduled tribe origin and 12 per cent to have a female head. Only 42 per cent of households had a private improved toilet. Twenty four per cent of households lived in urban areas. Finally, the highest 
percentages of households lived in Central and Eastern India and the lowest in Western and Southern India.

Regarding the intervention variables, 53 per cent of the sampled children received a food ration from the ICDS at least weekly, 31 per cent a health check-up and 27 per cent a weighing/measuring at the ICDS at least monthly, and 16 per cent regularly attended an ICDS preschool. In terms of livestock ownership, on average 43 per cent of households in Indian districts owned some livestock in 2011-12, but with a wide range from 0 to 92 per cent. The prevalence of cow ownership was 19 per cent and of poultry ownership 9 per cent.

\section{Results}

\subsection{Effects of children's dietary habits on their nutritional outcomes}

Results from the main regression models displayed in Table 2 (as well as the sensitivity analysis in Table 3 in the Appendix) show that from the key IYCF factors examined, weaning (=eating solid/semi-solid/mushy food) and minimum dietary diversity both have a consistently and robustly positive significant effect on the nutritional outcomes of 6-to-23-month-old Indian children. Weaning reduces their incidence of stunting, underweight as well as wasting ${ }^{3}$. Meanwhile, children fed a sufficiently diverse diet are less likely to be stunted, underweight, and potentially also wasted and anaemic than other children.

Theoretically, one could anticipate that most differences in IYCF feeding may be related to households' differing socio-economic circumstances and/or the region where they live. Poorer families may be unable to afford to provide a sufficiently diverse weaning diet to their toddlers whilst less educated mothers might be less aware of the existing recommendations on the ideal weaning age and diet. Similarly, some Indian regions may have distinct customs surrounding weaning and complementary feeding of children from other regions. Table 2 validates these expectations to some extent - the full models, which control for all socio-economic and regional variables, do show lower significance on most of the nutritional outcomes than the models excluding region or household-level socio-economic control variables. Nevertheless, in most cases, with the exception of the effects of satisfactory dietary diversity on wasting and anaemia, the significant effects remain even in the full models.

\footnotetext{
${ }^{3}$ However, this effect largely disappears in even younger children, as Table 4 in the Appendix analysing the effect of weaning on nutritional outcomes amongst 4- and 5-month-old children demonstrates.
} 
Table 2. The effects of IYCF on the nutritional outcomes of 6-23-month-old Indian children

\section{\begin{tabular}{|c|c|c|c|c|}
\hline Nutritional outcome & Stunted & Underweight & Wasted & Anaemic \\
\hline
\end{tabular}}

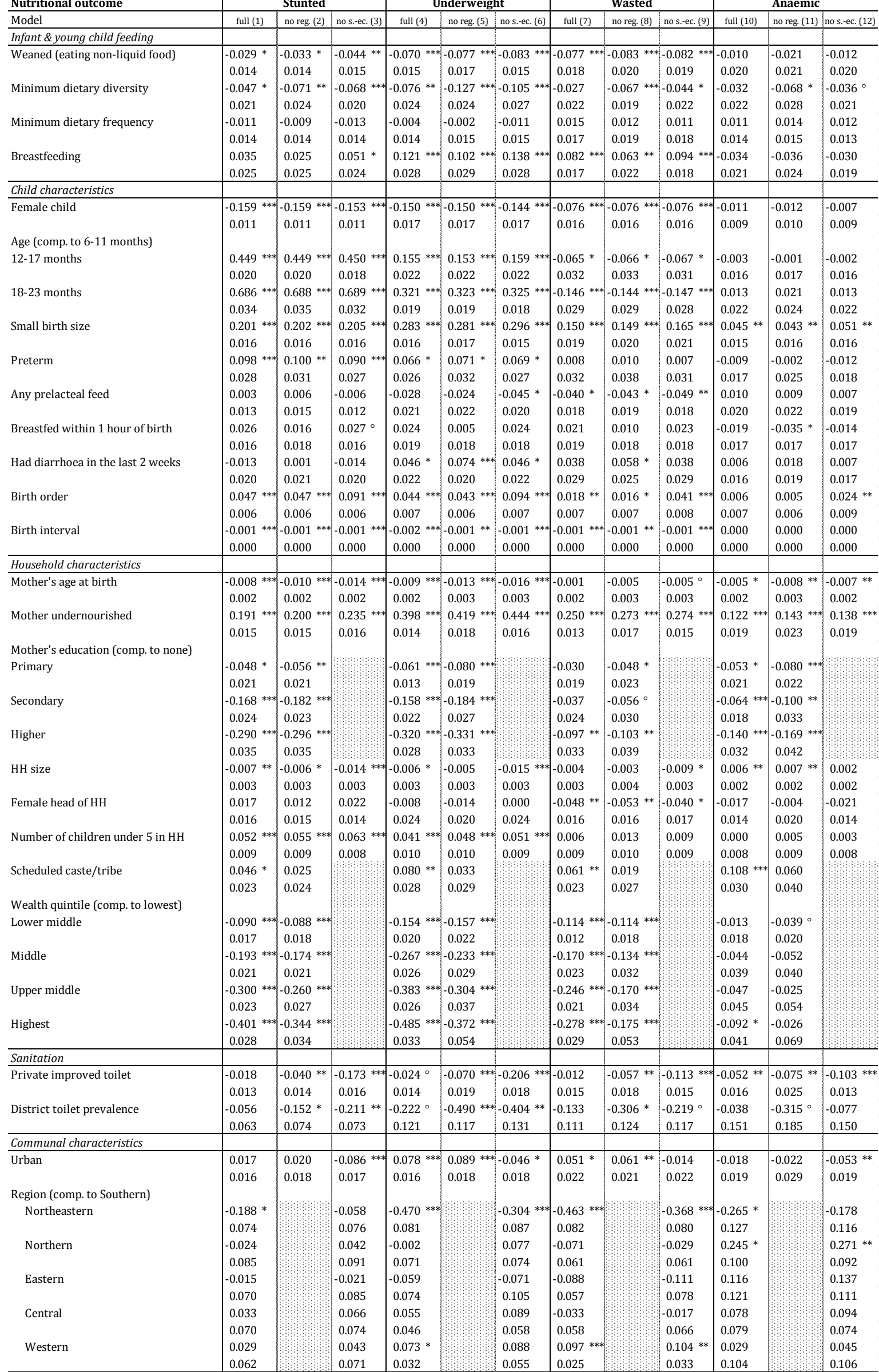

${ }^{* * *} p<0.0011^{* *} p<0.01{ }^{*} p<.05^{\circ} p<0.1$. All regressions were estimated using Probit regressions with standard errors clustered by Indian state.

The numbers next to the variables are coefficients, below are standard errors. The $\mathrm{N}$ for all regressions is 57,021 
Table 5. The percentage of 6-to-23-month-old Indian children weaned and fed a satisfactorily diverse diet across different wealth groups

\begin{tabular}{|c|c|c|c|c|c|}
\hline Wealth group & Lowest & Lower middle & Middle & Upper middle & Highest \\
\hline Weaned & $74 \%$ & $76 \%$ & $79 \%$ & $80 \%$ & $80 \%$ \\
\hline Satisf. diet. diversity & $15 \%$ & $20 \%$ & $23 \%$ & $25 \%$ & $25 \%$ \\
\hline
\end{tabular}

Analysis conducted on the same 57,021 children as analysed in regressions in Table 2.

Fig. 1. The effects of minimum dietary diversity on children's stunting and underweight across different wealth groups

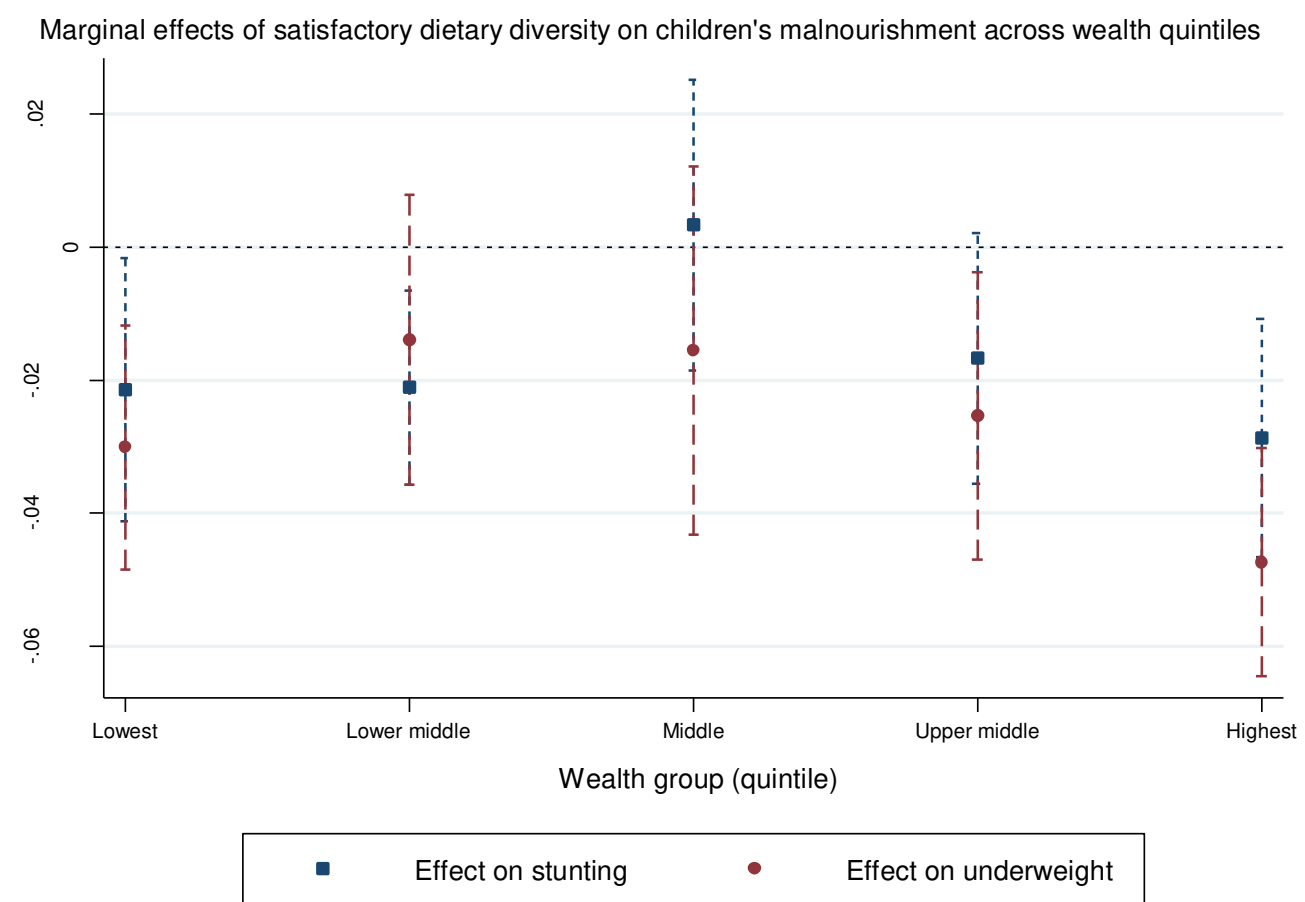

Marginal effects calculated from regressions akin to models (1) and (4) in Table 2, with the addition of an interaction term between satisfactory dietary diversity and households' wealth group

A deeper examination of the interaction between sufficient dietary diversity of complementary feeds and household's wealth quintile also demonstrates that it is not only in Indian households with low incomes where poor IYCF habits are negatively influencing children's nutritional outcomes. Table 5 shows that whilst a higher percentage of the wealthiest households follow the WHO IYCF guidelines than of the poorest households, large gaps remain even in the highest wealth group. For example, 20 per cent of 6-to-23-month-old Indian children in that group still receive only a liquid diet and 75 per cent were not fed a sufficiently diverse diet in the 24 hours prior to the survey. Furthermore, Figure 1 reveals that feeding toddlers the minimally diverse diet would significantly reduce the incidence of child stunting not only in the lowest two wealth groups but also in the highest one. Similarly, it would reduce children's underweight rates not only in the poorest but also in the two wealthiest groups. 
In contrast with weaning and minimum dietary diversity, neither of the other two IYCF factors examined - minimum dietary frequency and breastfeeding - appear to improve children's nutritional outcomes. Minimum dietary frequency has a negative relationship with stunting and underweight as expected but not a significant one. Breastfeeding, at first look counter-intuitively, seems to actually increase the prevalence of underweight and wasting. A closer look into the effects of breastfeeding on stunting, underweight, and wasting by age groups, displayed in Figure 2, shows, however, that the positive link is only significant for underweight and wasting in children older than 12 months and for stunting only for children older than 18 months $^{4}$. Previous research has suggested that such findings could be due to a lower nutrient quality of breastfed children's complementary feeds (Teshome et al. 2009) or due to reverse causality - i.e. where women with small/and or thin children continue breastfeeding longer to try to support their children's growth (Krasevec et al. 2016). In other words, it is not breastfeeding that leads to children's negative nutritional outcomes in that case but the negative nutritional outcomes that inspire prolonged breastfeeding.

Fig. 2. The effects of breastfeeding on children's nutritional outcomes by age groups

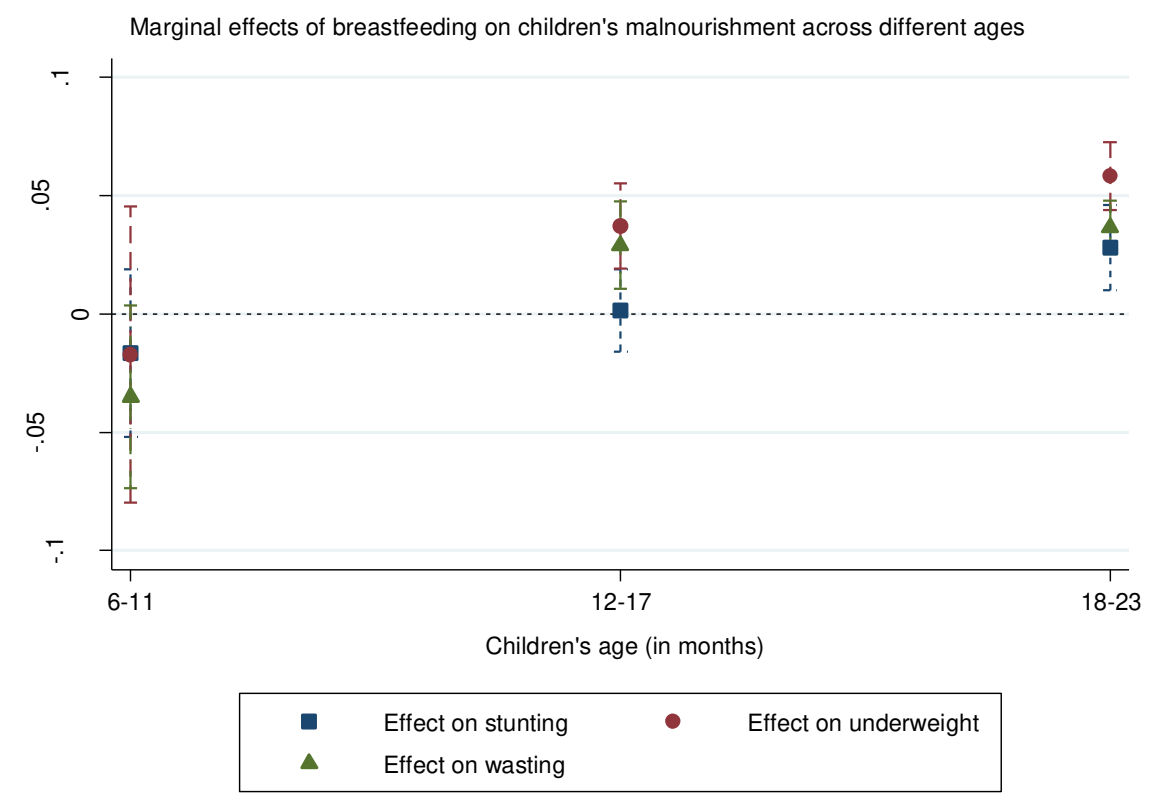

Marginal effects calculated from regressions akin to models (1), (4), and (7) in Table 2, with the addition of an interaction term between breastfeeding and children's age group

\subsection{Effects of weaning food groups on children's nutritional outcomes}

The results presented thus far have shown that feeding toddlers (semi)solid or mushy foods of sufficient variety improves their nutritional status; however, do the types of food consumed matter

\footnotetext{
${ }^{4}$ For children under one year old, breastfeeding has a more expected negative, albeit not significant, effect on malnutrition rates. The lack of significance may also be driven by the fact that the vast majority of such young children's mothers breastfeed their children.
} 
as well? In order to interrogate this question, I first estimated the same models as in Table 2, but with the addition of food groups that children received in mushy or (semi)solid form the day before the survey. The upper part of Table 6 shows the results and suggests that eating Vitamin-A-rich fruits and vegetables lowers children's prevalence of underweight and wasting and eating other fruits and vegetables reduces their risk of anaemia.

Table 6. The effects of different weaning food groups on children's nutritional outcomes

\begin{tabular}{|c|c|c|c|c|}
\hline & Stunted (1) & Underweight (2) & Wasted (3) & Anaemic (4) \\
\hline \multirow[t]{2}{*}{ Flesh foods } & $-0.084^{* *}$ & $-0.138^{* * *}$ & $-0.082^{\circ}$ & $-0.117^{* *}$ \\
\hline & 0.028 & 0.041 & 0.048 & 0.041 \\
\hline \multirow[t]{2}{*}{ Eggs } & $-0.042^{\circ}$ & -0.035 & -0.016 & -0.036 \\
\hline & 0.023 & 0.031 & 0.030 & 0.037 \\
\hline \multirow[t]{2}{*}{ Dairy foods } & $-0.035 *$ & $-0.041^{\circ}$ & 0.021 & -0.019 \\
\hline & 0.017 & 0.022 & 0.021 & 0.025 \\
\hline \multirow[t]{2}{*}{ Legumes and nuts } & 0.005 & -0.026 & -0.027 & 0.022 \\
\hline & 0.021 & 0.021 & 0.026 & 0.013 \\
\hline \multirow[t]{2}{*}{ Grains, roots, and tubers } & -0.005 & 0.021 & 0.025 & -0.008 \\
\hline & 0.020 & 0.039 & 0.030 & 0.034 \\
\hline \multirow[t]{2}{*}{ Vitamin-A rich plants } & -0.005 & $-0.044 * *$ & $-0.033 *$ & 0.023 \\
\hline & 0.017 & 0.016 & 0.016 & 0.015 \\
\hline \multirow[t]{2}{*}{ Other plants/foods } & -0.013 & -0.021 & -0.005 & $-0.045^{* *}$ \\
\hline & 0.018 & 0.022 & 0.021 & 0.014 \\
\hline \multirow[t]{2}{*}{ Any animal-source food } & $-0.072 * * *$ & $-0.076^{* * *}$ & -0.002 & $-0.059^{* *}$ \\
\hline & 0.015 & 0.016 & 0.018 & 0.022 \\
\hline \multirow[t]{2}{*}{ Flesh and eggs } & $-0.145^{* * *}$ & $-0.099^{*}$ & 0.004 & $-0.130^{*}$ \\
\hline & 0.038 & 0.047 & 0.037 & 0.052 \\
\hline \multirow[t]{2}{*}{ Flesh and dairy } & $-0.068^{\circ}$ & $-0.172 * * *$ & -0.016 & -0.047 \\
\hline & 0.038 & 0.047 & 0.054 & 0.057 \\
\hline \multirow[t]{2}{*}{ Eggs and dairy } & -0.006 & $-0.055^{\circ}$ & -0.021 & -0.040 \\
\hline & 0.042 & 0.033 & 0.034 & 0.038 \\
\hline \multirow[t]{2}{*}{ Flesh, eggs, and dairy } & $-0.104^{* * *}$ & $-0.139 *$ & -0.016 & $-0.073^{\circ}$ \\
\hline & 0.033 & 0.056 & 0.051 & 0.040 \\
\hline
\end{tabular}

${ }^{* * *} p<0.001^{* *} p<0.01^{*} p<.05^{\circ} p<0.1$

The numbers next to the variables are coefficients, below are standard errors. The $\mathrm{N}$ for all regressions is 57,021 .

The coefficients are derived from regressions akin to (1), (4), (7), and (10) in Table 2, with the addition of the specific variables (or their interaction) displayed in this table and the subtraction of satisfactory dietary diversity.

However, weaning with animal-source foods appears to be particularly effective in reducing the incidence of stunting. In addition, the consumption of flesh foods also reduces the incidence of underweight, wasting, and anaemia. Similarly, children who received at least one type of animalsource foods (flesh foods, eggs or dairy) the day before the survey were significantly less likely to be stunted, underweight or anaemic than children who did not receive such foods (middle of Table 5). The consumption of all three animal-source foods did not have the most positive effect on the children's nutritional status, as suggested by Headey et al. (2018), but the combination of flesh foods 
and eggs appears to reduce the risk of stunting the most; for the risk of underweight, the same is true of the combination of flesh foods and dairy (bottom part of Table 5).

Figure 3 displays the scale of the positive effects of weaning with animal-source foods on children's nutritional outcomes graphically. Figure 3a shows that, ceteris paribus, the incidence of stunting amongst children fed no animal-source foods was 38 per cent, in contrast with the 31-percent incidence amongst children fed both flesh foods and eggs. Analogously, Figure $3 \mathrm{~b}$ demonstrates that the prevalence of underweight amongst children fed both dairy and flesh foods ( 26 per cent) was, holding other factors constant, eight percentage points lowers than amongst children fed no animalsource foods (34 per cent).

Fig. $3(a, b)$. Effects of different animal-source foods on children's nutritional outcomes

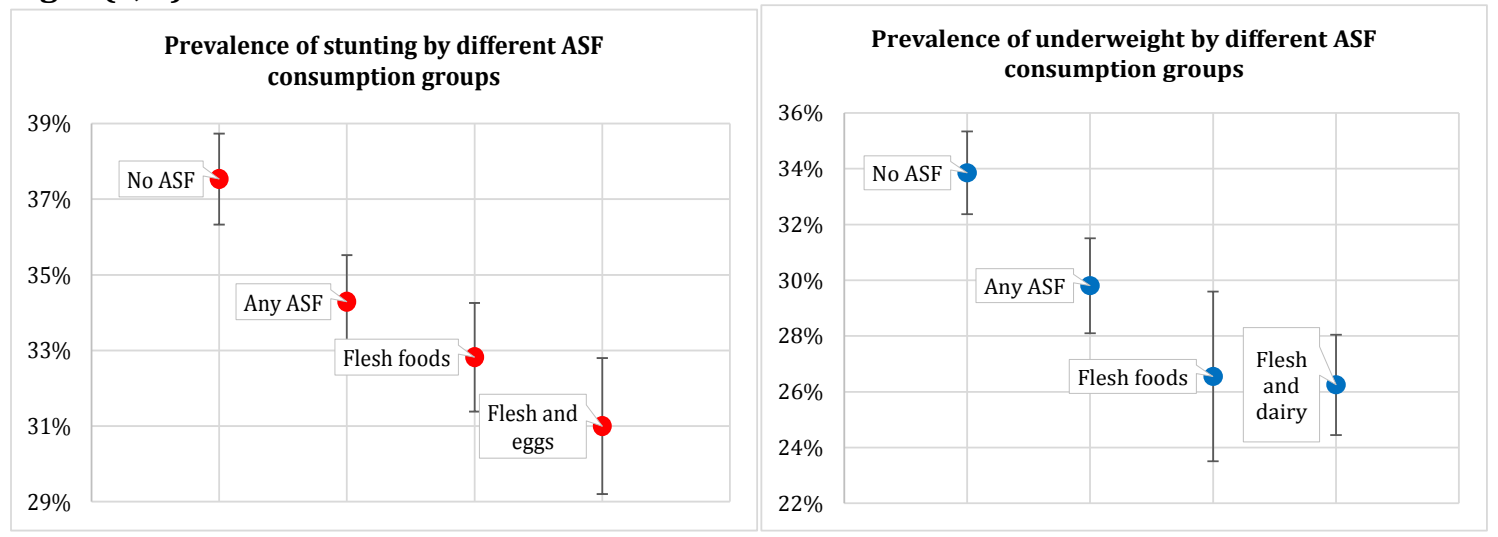

Figures display effects estimated from regressions (1) an (2) in Table 6.

\subsection{Other determinants of children's malnutrition}

Before examining whether ICDS and livestock ownership might make a difference in encouraging beneficial feeding habits of Indian children, let us briefly discuss factors other than IYCF that significantly influence Indian children's nutritional outcomes. Going back to Table 2, we look first at the influence of sanitation, which has been recently highlighted as one of the potentially key reasons underlying India's high undernourishment rates amongst children. Having access to a private improved toilet seems to reduce the prevalence of underweight and anaemia in children in the full models; nevertheless, in models that do not control for the Indian region of residence, having a private improved toilet has a significant reductive effect on all four measures of children's malnutrition. It is similarly so with the measure of public sanitation, the prevalence of private toilets in a district ${ }^{5}$. In the full models, district toilet prevalence significantly reduces only the incidence of underweight; however, when regional controls are excluded, the variable has a significant negative impact on all

\footnotetext{
${ }^{5}$ The idea behind the inclusion of the variable is that even if a household has access to a private sanitary facility, unless most other households in the area do so as well, there is still a risk of ground water contamination with faecal bacteria and all its related negative consequences (e.g. Spears et al. 2013).
} 
four malnutrition measures. Both private and public good sanitation is thus clearly important for positive nutritional outcomes amongst children and its provision seems to significantly vary by Indian region. Given that between the collection of the NFHS IV data in 2015-16 and 2019 India had implemented the nation-wide sanitation scheme Swachh Bharat and declared itself open-defecation free $^{6}$ (with all households having access to an improved, even if not necessarily private, toilet), there is hope that Indian children's nutritional outcomes will have in that short time period also improved considerably.

From child-level control variables, gender, age, birth status, and birth order all have a significant effect on nutritional outcomes. Girl children, despite being traditionally on average comparatively neglected by Indian parents (e.g. Lone et al. 2019), are less likely to be stunted, underweight or wasted than male children between the ages of 6 months and two years. This fits with previous research findings (Gupta et al. 2016, Jeyakumar et al. 2019, Kumar et al. 2006). The effect of age is more heterogeneous, with stunting and underweight higher in the later age groups whilst wasting lower. Children born prematurely and/or very small at birth are at a higher risk of deficient nutritional status than other children. Finally, higher-order children are also more likely to be malnourished, particularly if the interval with the preceding sibling is small. These results all align with existing literature. That is not quite true vis-à-vis findings on pre-lacteal feeds and not being breastfed within one hour of birth, which in this study do not appear to have significantly exacerbated children's nutritional outcomes ${ }^{7}$.

Turning to household and communal factors, children with older, more educated mothers tend to be better nourished, as do children living in bigger households - but not with many children under five. Children in wealthier households are, unsurprisingly, at a lower risk of deficient nutritional outcomes. In contrast, children in households from scheduled castes or tribes are more prone to malnourishment, even after controlling for wealth. Urban children and children in Western Indian states (particularly Maharashtra, Gujarat, and Goa), are, ceteris paribus, more likely to be underweight and wasted than their counterparts. Children in Northeastern Indian states are, in contrast, the least likely to be malnourished.

\footnotetext{
${ }^{6}$ India's National Statistical Office survey results somewhat debunked the claim, indicating that even after the completion of Swachh Bharat almost 30 per cent of households still lacked access to improved toilets (Jebaraj 2019). That is, however, still a significant improvement compared to the NFHS IV (2015-16), when more than 50 per cent of households lacked such access.

7 Immunisation status also did not appear to have a significant effect on nutritional outcomes and was eventually not included in the models.
} 


\subsection{Effects of ICDS and livestock ownership on children's dietary habits and nutritional outcomes}

Turning now to the examination of factors that could enhance IYCF habits found to have a positive nutritional impact on children - weaning, satisfactory dietary diversity, and the consumption of animal-source foods - I focus on children's participation in the ICDS, India's largest national programme aimed at promoting children's health, and on livestock ownership, as animal proteins may be unaffordable to many families in India if not produced within their own homes or possibly purchased in neighbourhood markets from local producers.

Regarding ICDS, I examined the effects of four types of its services - the provision of a food ration to children at least once a week, the provision of a health check-up and a weighing/measuring service at least once a month, and the provision of regular pre-school education - on recipient children's beneficial dietary habits and nutritional outcomes. This was done using Propensity Score Matching, with the five-nearest neighbour's approach ${ }^{8}$. The upper part of Table 7 shows that whilst ICDS services do not appear to have encouraged participating parents to introduce their toddlers to (semi)solid or mushy foods promptly after the recommended 6 months of age, some of the services have apparently increased the consumption of a sufficiently varied diet and of animal-source foods. The pathway mechanism probably differs for different services, however. Whereas ICDS likely contributed to satisfactory dietary diversity of its regular food-ration recipients and pre-school attendees directly, by providing them with varied meals, the positive effects of monthly health checkups on dietary diversity and consumption of animal-source foods are more likely to have occurred indirectly, via dispensing nutritional advice to the children's parents.

Nevertheless, these positive nutritional habits do not seem to have brought about improvements in children's nutritional outcomes. ICDS recipients appear to suffer from malnutrition at rates no lower than their counterparts in the control group. Children receiving regular ICDS health check-ups have even slightly higher rates of stunting and anaemia than non-recipients. This should not be taken as an indication that the ICDS actually exacerbates children's nutritional outcomes, however. It may be rather a case of reverse causality, with malnourished children's parents likely more drawn to ICDS services than other parents, and perhaps particularly so in the case of the medical check-ups. The PSM approach attempts to eliminate reverse causality by matching treated and nontreated cases on a whole suite of observable characteristics but it cannot control for unobservable characteristics, which may have made the difference here. The fact that the ICDS recipient children receive a more varied diet and more animal-source foods than non-treated matched counterparts

\footnotetext{
8 PSM with the nearest-neighbour approach was used as a robustness check, the results of which can be found in Table 8 in the Appendix.
} 
nonetheless raises hope that over time the ICDS may have a notably positive impact also on children's nutritional outcomes.

Regarding the effects of the district prevalence of livestock ownership on children's nutritional habits and outcomes (lower part of Table 7), neither general livestock nor cow ownership appear to have any significant positive effects. Nevertheless, district-level prevalence of poultry ownership does. Not only does poultry ownership increase the consumption of animal-source foods, flesh foods, and eggs, it also appears to reduce the risk of stunting and underweight. This is true across wealth groups - Figure 4 shows that in all wealth quintiles, going from minimal district-level poultry ownership ( 0 per cent) to a maximum one (65 per cent), whilst holding other factors constant, would increase children's consumption of flesh foods two to three times and reduce their stunting prevalence by 10 to 20 percentage points. High prevalence of poultry ownership in a district may reflect a reality where a lot of otherwise poor households may own their own flocks of birds and thus have an easy access to at least an occasional cheap source of protein, through the birds' flesh and more frequently eggs. However, even if poor households in such a district do not own poultry directly, they may be buying the birds' eggs and meat from other households more cheaply than are available in districts with a low prevalence of poultry ownership. Interestingly, however, the effect of poultry ownership on both the consumption of flesh foods and stunting is stronger in the wealthiest household quintile. This could be due to a greater local availability and affordability of chicken meat and eggs as well; nevertheless, it could also be due to a culture more encouraging of animal-source food consumption than in districts with low poultry ownership.

Table 7. Effects of ICDS/livestock ownership on children's feeding habits and nutritional outcomes

\begin{tabular}{|c|c|c|c|c|c|c|c|}
\hline \multirow[t]{2}{*}{ ICDS } & \multirow[b]{2}{*}{ Weaned (1) } & \multirow[b]{2}{*}{$\begin{array}{c}\text { Satis. diet. } \\
\text { diversity (2) }\end{array}$} & \multirow[b]{2}{*}{ Any ASF (3) } & \multirow[b]{2}{*}{ Stunted (4) } & \multirow[b]{2}{*}{ Underweight (5) } & \multirow[b]{2}{*}{ Wasted (6) } & \multirow[b]{2}{*}{ Anaemic (7) } \\
\hline & & & & & & & \\
\hline \multirow[t]{2}{*}{ Food at least weekly } & & $0.042 * * *$ & 0.013 & 0.015 & -0.008 & 0.017 & 0.000 \\
\hline & & 0.011 & 0.013 & 0.013 & 0.013 & 0.011 & 0.014 \\
\hline \multirow[t]{2}{*}{ Health check-up at least monthly } & $-0.014^{\circ}$ & $0.023^{* *}$ & $0.022 *$ & $0.015^{\circ}$ & 0.010 & -0.004 & $0.018^{\circ}$ \\
\hline & 0.008 & 0.007 & 0.022 & 0.009 & 0.009 & 0.008 & 0.009 \\
\hline \multirow[t]{2}{*}{ Weight/height check at least monthly } & -0.001 & -0.005 & -0.006 & 0.008 & -0.003 & 0.001 & 0.009 \\
\hline & 0.007 & 0.007 & 0.008 & 0.008 & 0.008 & 0.007 & 0.008 \\
\hline \multirow[t]{2}{*}{ Regular ICDS preschool attendance } & $-0.029^{* * *}$ & $0.019^{* *}$ & $0.018^{* *}$ & 0.004 & -0.001 & 0.005 & 0.004 \\
\hline & 0.006 & 0.006 & 0.007 & 0.007 & 0.007 & 0.006 & 0.007 \\
\hline \multicolumn{8}{|l|}{ Livestock ownership } \\
\hline & Any ASF (8) & Flesh (9) & $\begin{array}{l}\text { Eggs (poultry), } \\
\text { dairy (cows) (10) }\end{array}$ & Stunted (11) & Underweight (12) & Wasted (13) & Anaemic (14) \\
\hline \multirow[t]{2}{*}{ Livestock ownership in district (\%) } & $-0.414^{*}$ & $-0.647^{\circ}$ & & 0.022 & -0.019 & -0.070 & 0.007 \\
\hline & 0.202 & 0.360 & & 0.089 & 0.137 & 0.139 & 0.172 \\
\hline \multirow[t]{2}{*}{ Cow ownership in district (\%) } & -0.330 & -0.675 & -0.038 & -0.107 & -0.123 & 0.030 & -0.002 \\
\hline & 0.374 & 0.552 & 0.296 & 0.094 & 0.199 & 0.193 & 0.176 \\
\hline \multirow[t]{2}{*}{ Poultry ownership in district (\%) } & $0.993 * *$ & $1.546^{* * *}$ & $1.213 *$ & $-0.523 * * *$ & $-0.586 *$ & -0.351 & -0.438 \\
\hline & 0.366 & 0.436 & 0.522 & 0.135 & 0.273 & 0.256 & 0.317 \\
\hline
\end{tabular}

${ }^{* * *} p<0.001^{* *} p<0.01^{*} p<.05^{\circ} p<0.1$

The numbers next to the variables are coefficients, below are standard errors. The effects of the different 'ICDS treatments' were estimated using Propensity Score matching (five-nearest-neighbours approach). The effects of livestock ownership were estimated using Probit regressions with state-clustered standard errors, akin to the full models in Table 2 but with the addition of the livestock variables (each was estimated separately). 
Fig. 4. The effects of district poultry ownership on children eating flesh foods
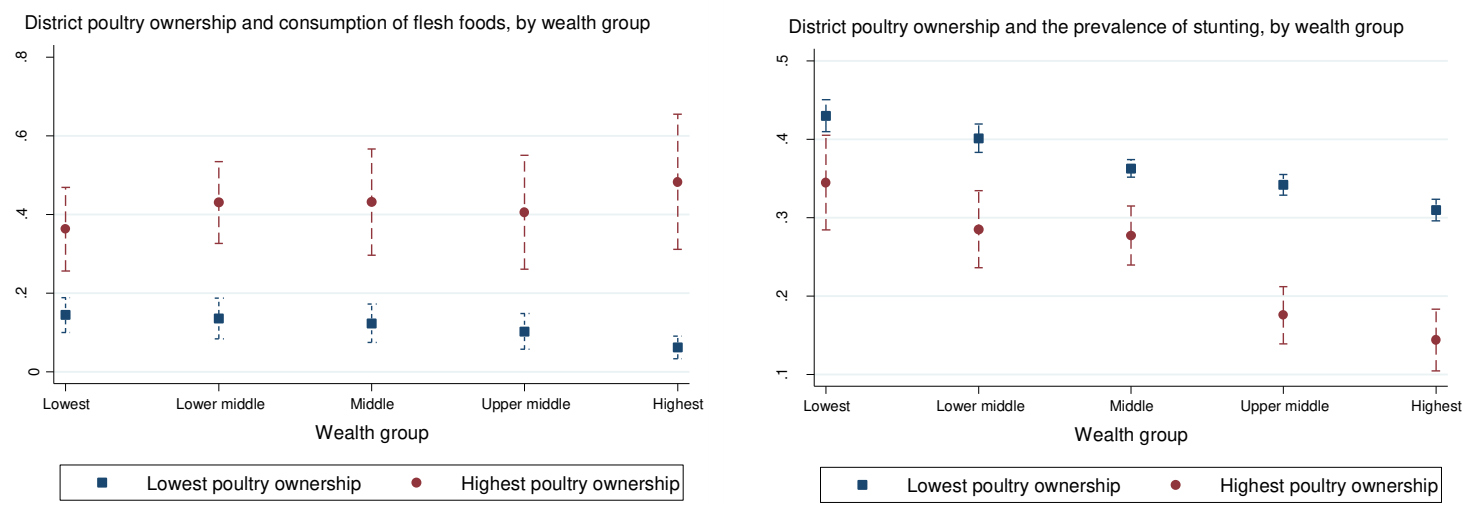

Marginal effects from regressions akin to (9) and (11) in Table 7, with the addition of an interaction term between poultry ownership and households' wealth group.

\section{Discussion and conclusions}

Despite significant economic growth in the past few decades, India has continued to experience significantly higher levels of child malnutrition rates than many economically poorer countries. Even the gradual albeit slow improvement on this front over recent years is now threatened by the Covid-19 pandemic and its associated effects. Due to an economic decline in many sections of the society coupled with a reduction in child-focused nutrition interventions, Headey et al. (2020) have recently predicted a rapid surge in India's child wasting rates in the next year. On the same basis, deterioration can be expected also in the other nutritional outcome measures.

Now is thus a particularly important time to deepen our understanding of the drivers of India's high child malnourishment rates, which is what this study has sought to do through a comprehensive examination of nationally representative data from more than 57,000 Indian children. The specific aim of the analysis was to assess how feeding practices amongst Indian toddlers (6 to 23 months old) affected their nutritional outcomes. The initial focus was on four key WHO-recommended practices continued breastfeeding, weaning/feeding (semi)solid or mushy foods to children from 6 months onwards, and feeding them sufficiently frequently and a sufficiently varied array of different foods. Out of those practices, feeding children older than 6 months a diverse diet of (semi)solid or mushy foods turned out to consistently and significantly help improve their nutritional status. Doing so prior to 6 months of age did not appear to increase the incidence of malnutrition as suggested by some previous research (Bhutia 2014, Gupta et al. 2015) but equally did not have a significantly positive effect (Teshome et al. 2009, Vyas et al. 2014). Socio-economic variables were found to play a mediating role in the beneficial dietary habits, with wealthier households and more educated mothers more likely to wean their children on time and feed them more diverse foods. Nevertheless, much of the malpractice in child feeding cut across the socio-economic lines, with 75 per cent of households 
even in the wealthiest quintile and 73 per cent of mothers with higher education still not providing their toddlers with the WHO-recommended minimum diverse diet.

The next step in the analysis was to examine whether the specific types of food consumed by weaned children had any effect on their nutritional outcomes. Children who consumed Vitamin A-rich fruits and vegetables were found to be less likely to suffer from underweight and wasting and those who ate other fruits and vegetables less likely to be anaemic. However, it was the consumption of animal-source foods that had a particularly strong reductive effect on children's malnutrition rates, with children that ate at least one such source the day before at a significantly lower risk of stunting, underweight, and anaemia. Existing cross-country research has highlighted the importance of animalsource foods in improving children's nutritional outcomes (e.g. Headey et al. 2018, Krasevec et al. 2016), due to the foods' high content of protein as well as micronutrients such as vitamin D, calcium, and zinc. That research also indicated that the effect of animal-source foods may be cumulative, i.e. that consumption of all three types (flesh, dairy, and eggs) might have the most positive impact. That was not quite validated by this study's findings; nevertheless, the effects of some animal-source-food combinations on the incidence of child malnutrition appeared indeed very notable. Compared to children not eating any animal-source foods, children who ate both meat and eggs were found to be 18 per cent less likely to be stunted and children who ate both meat and dairy 24 per cent less likely to be underweight.

Having identified dietary habits supportive of positive nutritional outcomes, the study examined two potential 'remedies' - participation in the ICDS and livestock ownership. The ICDS is India's largest national programme aimed at improving nutritional outcomes amongst pregnant and breastfeeding mothers and young children. Through a dense network of anganwadi centres, the programme provides supplementary nutrition and health services to children under six years old, nutritional and health education to mothers, and growth monitoring, de-worming, and pre-school education to children (Lokshin et al. 2005). I considered the effects of four specific ICDS services weekly food rations, monthly health check-ups, monthly weighting/measuring, and regular pre-school attendance - on both children's beneficial dietary habits and their malnutrition rates. Existing research on ICDS' impact on children's nutritional outcomes has been mixed, with some finding no significant effect (e.g. Kandpal 2011, Kumar et al. 2006) whilst others pointing to a positive effect on children's height (Jain 2015) or weight (Mittal and Meenakshi 2019). In the 6-23-month-old cohort of children from the NFHS IV examined in this study, none of the ICDS services examined appear to have significantly reduced negative nutritional outcomes. However, they do appear to have increased children's dietary diversity and consumption of animal-source foods, both directly through food rations and indirectly through nutritional advice. It is possible that these beneficial practices do 
eventually translate into long-term nutritional improvements as well, but that is something a crosssectional study like this one cannot easily capture.

Where it appears that the ICDS could do better is in encouraging parents to start with complementary feeding promptly after children turn 6 months of age. Manikam et al.'s (2017) review of IYFC practices in South Asia noted that health care professionals, including ICDS staff, are cited as the number one source of nutritional advice that parents receive. The number two source are family members, however, and their advice, frequently based on traditional beliefs, is often wrong. Common erroneous ideas about complementary feeding have included insistence that it should not be started before a child turns one year old and that 'children cannot tolerate animal-based proteins until 18 months of age' (Manikam et al. 2017: 651). The ICDS with its vast network of anganwadi centres is theoretically in a good position to affect significant positive change in parental awareness of beneficial child-feeding practices; however, the programme has been historically underfunded and plagued by low staff retention rates, also due to very low wages paid to its employees (Singh 2019). Addressing these issues would likely enable the national government to significantly boost children's nutrition security across India.

As a second 'remedy', inspired by the finding of a strong link between the consumption of animalsource foods and reduced incidence of child malnutrition, the study examined the relationship between livestock ownership on the one side and children's feeding habits and nutritional outcomes on the other. The underlying rationale for this assessment was that expensive animal proteins may be more likely to be consumed by households if they either produce them themselves or purchase them locally. I did not find this to hold true for either a general measure of livestock ownership or for cow ownership. Nevertheless, the district-level prevalence of poultry ownership was found to have a significant effect on feeding habits - increasing the consumption of flesh foods and eggs - as well as on nutritional outcomes, specifically reducing the risk of stunting and underweight. This was true across wealth groups, pointing to a greater affordability of animal proteins in areas where many families keep chickens and likely also to a greater acceptance of consuming animal-source foods in such areas ${ }^{9}$. Whilst backyard poultry farming has been shown not to significantly reduce economic poverty in India's rural areas (Pica-Ciamarra and Otte 2010), it seems to have a significantly more positive effect on local children's nutrition and thus public programmes supporting it would constitute a worthy government investment.

The third 'remedy' that was not examined in this study due to a lack of relevant data (and space) but could have a potentially far-reaching impact on Indian children's nutrition is India's Public

\footnotetext{
${ }^{9} \mathrm{~A}$ large portion of the Indian population is vegetarian; however, some Indian vegetarians eat eggs whilst others do not. It is likely that vegetarians living in areas with high prevalence of poultry ownership are more accepting of eating eggs than vegetarians elsewhere.
} 
Distribution System (PDS). This national food subsidy programme was significantly expanded after the passing of India's National Food Security Act in 2013 and currently covers about two-thirds of India's population, allowing them to purchase a certain amount of cereals, oil, sugar, and sometimes pulses at highly subsidised prices every month (Kumar et al. 2017, Petrikova 2018). However, the programme has not been found to increase the diversity of households' diets (Desai and Vanneman 2015) and hence likely does not strengthen children's nutrition security. In an article describing the weaning practices amongst migrant tribal communities in Rajasthan, Mohan et al. (2016) found that although most households surveyed were PDS beneficiaries and had access to cereals, only 14 per cent had any vegetables in the house, 2 per cent had fruits, and almost none had any milk, eggs or meat. If the PDS increased the variety of foods it subsidises to include also vegetables, fruits, and animal-source foods, it could likely also contribute to better nutritional outcomes amongst children.

This article aimed to deepen existing understanding of the drivers of India's internationally high child malnutrition rates through a nationally representative look at the links between IYCF and the nutritional outcomes amongst 6-to-23 month-old children. The study found that feeding children (semi)solid or mushy foods from 6 months of age and feeding them a sufficiently diverse diet, including animal-source foods, significantly reduced their risk of malnutrition. The ICDS was found to be somewhat beneficial in encouraging parents to follow the beneficial dietary habits but could be more so, likely if it were better funded and supported by the government. Backyard poultry ownership could also be supported by the government as a means of increasing animal-source consumptions across wealth groups and thus also improving children's nutritional outcomes. Finally, whilst the PDS were not examined empirically in this study, if the programme widened its provision from cereals, sugar, oil, and pulses to include also vegetables, fruits, and animal-source foods, it would likely be able to contribute to children's nutrition security more than it has thus far. 


\section{Conflicts of interest}

No conflicts of interest to report. 


\section{References}

Amsalu, S., \& Tigabu, Z. (2008). Risk factors for acute malnutrition in children under the age of five. Ethiopian Journal of Health Development, 22(1), 21-25.

Bhandari, N., Bahl, R., Taneja, S., de Onis, M., \& Bhan, M. Growth performance of affluent Indian children. Bulletin of the World Health Organisation, 80, 189-195.

Bharati, S., Pal, M., Sen, S., \& Bharati, P. (2018). Growth and nutritional status of preschool children in India. In R. Dasgupta (Ed.), Advances in growth curve and structural equation modelling (pp. 113125). Singapore: Springer.

Bhutia, D. T. (2014). Protein energy malnutrition in India: The plight of our under-five children. Journal of Family Medicine and Primary Care, 3(1), 63-67.

Bukusuba, J., Kaaya, A. N., \& Atukwase, A. (2017). Risk factors for stunted growth among children aged 6-59 months in rural Uganda. International Journal of Nutrition, 2(3), 1-13.

Desai, S., \& Vanneman, R. (2015). Enhancing nutrition security via India's National Food Security Act: Using an axe instead of a scalpel? India Policy Forum, 11, 67-113.

Dewey, K., \& Begum, K. (2011). Long-term consequences of stunting in early life. Maternal \& Child Nutrition, 7(S3), 5-18.

Godhia, M., \& Patel, N. (2013). Colostrum - its composition, benefits as a nutraceutical - a review. Current Research in Nutrition and Food Science Journal, 1(1), 37-47.

Jeyakumar, A., Supriya, N., \& Nayak, S. (2019). Prevalence and risk factors of undernutrition among children less than 2 years in urban slums of Pune, Maharashtra, India. Ecology of Food and Nutrition. DOI: 10.1080/03670244.2019.1613985.

Gupta, A., Kalaivani, M., Gupta, S., Rai, S., \& Nongkynrih, B. (2015). Burden of undernutrition, composite index of anthropometric failure and perception of caregivers about undernutrition among under-five children in rural India. Indian Journal of Nutrition and Dietetics, 52(2), 140-152.

GHI (2019). https://www.globalhungerindex.org/. Accessed 15 July 2020.

Headey, D., Hoddinott, J., Ali, D., Tesfaye, R., \& Dereje, M. (2015). The other Asian enigma: Explaining the rapid reduction of undernutrition in Bangladesh. World Development, 66, 749-761.

Headey, D., Hirvonen, K., \& Hoddinott, J. (2018). Animal sourced foods and child stunting. American Journal of Agricultural Economics, 100(5), 1302-1319.

Headey, D., Heidkamp, R., Osendarp, S., Ruel, M., Scott, N., Black, R., Shekar, M., Bouis, H., Flory, A., Haddad, L., \& Walker, N. (2020). Impacts of COVID-19 on childhood malnutrition and nutritionrelated mortality. The Lancet. https://doi.org/10.1016/ S0140-6736(20)31647-0.

Hruschka, D. J., \& Hadley, C. (2016). How much do universal anthropometric standards bias the global monitoring of obesity and undernutrition? Obesity Reviews, 17(11), 1030-1039. 
Jain, M. (2015). India's struggle against malnutrition-Is the ICDS program the answer? World Development, 67, 72-89.

Jayant, D. D., Purushottam, G. A., Deepak, P. B., Vaishali, P. D., Piyush, K., \& Aarif, S. M. (2010). Sociocultural practices in relation to breastfeeding, weaning and child rearing among Indian mothers and assessment of nutritional status of children under five in rural India. Australasian Medical Journal, 3(9), 618-624.

Jebaraj, P. (2019, November 24). Open defecation-free India: National Statistical Office survey debunks Swachh Bharat claims. The Hindu. https://www.thehindu.com/news/national/opendefecation-free-india-national-statistical-office-survey-debunks-swachh-bharatclaims/article30070689.ece.

Kandpal, E. (2011). Beyond average treatment effects: Distribution of child nutrition outcomes and program placement in India's ICDS. World Development, 39(8), 1410-1421.

Krasevec, J., An, X., Kumapley, R., Bégin, F., \& Frongillo, E. A. (2017). Diet quality and risk of stunting among infants and young children in low-and middle-income countries. Maternal \& Child Nutrition, 13, e12430.

Kumar, D., Goel, N., Mittal, P., \& Misra, P. (2006). Influence of infant-feeding practices on nutritional status of under-five children. Indian Journal of Pediatrics, 73(5), 417-421.

Kumar, A., Parappurathu, S., Babu, S. C., \& Joshi, P. K. (2017). Can better governance improve food security? An assessment of the public food distribution system in Odisha, India. Food Security, 9(6), $1433-1445$.

Lokshin, M., Das Gupta, M., Gragnolati, M., \& Ivaschenko, O. (2005). Improving child nutrition? The Integrated Child Development Services in India. Development and Change, 36(4), 613-640.

Lone, B., Lone, S., \& Mayer, I. (2019). Socio-economic vulnerability assessment of female children to malnutrition in rural Baramulla district of Kashmir Himalayas, India. GeoJournal, 85(2), 535-549.

Manikam, L., Prasad, A., Dharmaratnam, A., Moen, C., Robinson, A., Light, A., Ahmed, S., Lingam, R., \& Lakhanpaul, M. (2018). Systematic review of infant and young child complementary feeding practices in South Asian families: the India perspective. Public Health Nutrition, 21(4), 637-654.

Meshram, I. I., Rao, K. M., Balakrishna, N., Harikumar, R., Arlappa, N., Sreeramakrishna, K., \& Laxmaiah, A. (2019). Infant and young child feeding practices, sociodemographic factors and their association with nutritional status of children aged 3 years in India: Findings of the National Nutrition Monitoring Bureau survey, 2011-2012. Public Health Nutrition, 22(1), 104-114.

Mishra, K., Kumar, P., Basu, S., Rai, K., \& Aneja, S. (2014). Risk factors for severe acute malnutrition in children below five years of age in India. Indian Journal of Pediatrics, 81(8), 762-765. 
Mittal, N., \& Meenakshi, J. (2019). Does the ICDS improve children's diets? Some evidence from rural Bihar. Journal of Development Studies, 55(11), 2424-2439.

Mohan, P., Agarwal, K., \& Jain, P. (2016). Child malnutrition in Rajasthan. Economic \& Political Weekly, 51(3), 73-81.

NFHS IV (2017). http://rchiips.org/NFHS/factsheet_NFHS-4.shtml. Accessed 15 July 2020.

Padmadas, S., Hutter, I., \& Willekens, F. (2002). Weaning initiation patterns and subsequent linear growth progression among children aged 2-4 years in India. International Journal of Epidemiology, 31(4), 855-863.

Petrikova, I. (2018). Food-security governance in India and Ethiopia: A comparative analysis. Third World Quarterly, 40(4), 743-762.

Pica-Ciamarra, U., \& Otte, J. (2010). Poultry, food security and poverty in India: Looking beyond the farm-gate. World's Poultry Science Journal, 66(2), 309-320.

Ramalingaswami, V., Jonsson,U., \& Rohde, J. (1997) Malnutrition: A South Asian enigma. In Malnutrition in South Asia. Kathmandu: UNICEF.

Ravallion, M. (2001). The mystery of the vanishing benefits: An introduction to impact evaluation. World Bank Economic Review, 15(1), 115-140.

Roche, M. L., Gyorkos, T. W., Blouin, B., Marquis, G. S., Sarsoza, J., \& Kuhnlein, H. V. (2017). Infant and young child feeding practices and stunting in two highland provinces in Ecuador. Maternal \& Child Nutrition, 13(2), e12324.

Shamim, S., Naz, F., Jamalvi, W., \& Ali, S. (2006). Effect of weaning period on nutritional status of children. Journal of the College of Physicians and Surgeons Pakistan, 16(8), 529-531.

Singh, C. (2019, December 4). Lean budgets, thin children. The Telegraph India. https://www.telegraphindia.com/opinion/lean-budgets-thin-children/cid/1724012.

Spears, D. (2013). How much international variation in child height can sanitation explain? Washington, DC: The World Bank.

Spears, D., Ghosh, A., \& Cumming, O. (2013). Open defecation and childhood stunting in India. PloS One, 8(9), 1-9.

Spears, D., \& Haddad, L. (2015). Why sanitation matters for nutrition. http://motherchildnutrition.org/pdf/Why-sanitation-matters-for-nutrition-IFPRI-2015.pdf.

Teshome, B., Kogi-Makau, W., Getahun, Z., \& Taye, G. (2009). Magnitude and determinants of stunting in children under five years of age in food-surplus region of Ethiopia: The case of West Gojam zone. Ethiopian Journal of Health Development, 23(2), 98-106.

UNICEF (2017). First 1,000 days. https://www.unicef.org/southafrica/SAF_brief_1000days.pdf. Accessed 15 July, 2020. 
Vyas, S., Kandpal, S., Semwal, J., Chauhan, S., \& Nautiyal, V. (2014). Trends in weaning practices among infants and toddlers in a hilly terrain of a newly formed state of India. International Journal of Preventive Medicine, 5(6), 741-748.

WHO (2005). Complementary feeding. https://www.who.int/nutrition/topics/ complementary_feeding/en/. Accessed 15 July 2020.

WHO (2008). Indicators for assessing infant and young child feeding practices. https://apps.who.int/iris/bitstream/handle/10665/43895/9789241596664_eng.pdf?sequence=1. Accessed 15 July 2020.

WHO (2010). Nutrition landscape information system: Interpretation Guide. https://www.who.int/nutrition/nlis_interpretation_guide.pdf. Accessed 15 July, 2020.

WHO (2018). Infant and young child feeding. https://www.who.int/news-room/factsheets/detail/infant-and-young-child-feeding. Accessed 15 July 2020.

Yajnik, C. S., Fall, C. H. D., Coyaji, K. J., Hirve, S. S., Rao, S., Barker, D. J. P., Joglekar, C. \& Kellingray, S. (2003). Neonatal anthropometry: the thin-fat Indian baby. The Pune maternal nutrition study. International Journal of Obesity, 27(2), 173-180. 


\section{Appendix}

Table 3. Models from Table 2 estimated using multilevel logistic regressions

\begin{tabular}{|c|c|c|c|c|c|c|c|c|c|c|c|c|}
\hline \multirow{2}{*}{$\begin{array}{l}\text { Nutritional outcome } \\
\text { Model }\end{array}$} & \multicolumn{3}{|c|}{ Stunted } & & Jnderweigh & & & Wasted & & & Anaemic & \\
\hline & full (1) & no reg. (2) & no s.ec. (3) & full (4) & no reg. (5) & no s.ec. (6) & full (7) & no reg. (8) & no s.ec. (9) & full (10) & no reg. (11) & no s.ec. (12) \\
\hline Infant \& young child feeding & & & & & & & & & & & & \\
\hline Weaned (eating non-liquid food) & -0.034 & -0.034 & $-0.055 *$ & $-0.106^{* * *}$ & $-0.106 * *$ & $-0.122 * * *$ & $-0.130 * *$ & $-0.130 * *$ & * $-0.133 * * *$ & 0.000 & 0.000 & -0.003 \\
\hline Minimum dietary diversity & $-0.050 *$ & $-0.053 *$ & $-0.070^{* *}$ & $-0.086^{* *}$ & $-0.087 * *$ & $-0.116^{* * *}$ & -0.028 & -0.030 & -0.042 & $-0.047 *$ & $-0.048 *$ & $-0.055 *$ \\
\hline & 0.025 & 0.025 & 0.024 & 0.027 & 0.027 & 0.026 & 0.029 & 0.029 & 0.028 & 0.023 & 0.023 & 0.022 \\
\hline Minimum dietary frequency & -0.006 & -0.006 & -0.007 & 0.002 & 0.002 & -0.007 & 0.029 & 0.029 & 0.022 & 0.027 & 0.027 & 0.027 \\
\hline & 0.029 & 0.029 & 0.029 & 0.032 & 0.032 & 0.031 & 0.035 & 0.035 & 0.034 & 0.027 & 0.027 & 0.027 \\
\hline Child characteristics & & & & & & & & & & & & \\
\hline Female child & $-0.261^{* * *}$ & $-0.261^{* * *}$ & * $-0.250^{* * *}$ & $-0.249^{* * *}$ & $-0.249 * *$ & $-0.238 * * *$ & $-0.131^{* * *}$ & $-0.132 * *$ & * $-0.130^{* * *}$ & -0.017 & -0.017 & -0.011 \\
\hline & 0.018 & 0.018 & 0.018 & 0.019 & 0.019 & 0.019 & 0.020 & 0.020 & 0.020 & 0.017 & 0.017 & 0.016 \\
\hline Age (comp. to 6-11 months) & & & & & & & & & & & & \\
\hline $12-17$ months & $0.749^{* * *}$ & $0.749^{* * *}$ & 0.749 *** & $0.257^{* * * *}$ & $0.257^{* * *}$ & $0.264^{* * *}$ & $-0.115 * * *$ & $-0.116 * *$ & * $-0.120 * * *$ & -0.007 & -0.007 & -0.006 \\
\hline Preterm & $0.155^{* * *}$ & $0.155^{* * *}$ & 0.137 *** & 0.123 ** & $0.123^{* *}$ & $0.123^{* *}$ & 0.057 & 0.058 & 0.053 & 0.000 & 0.000 & -0.007 \\
\hline & 0.038 & 0.038 & 0.037 & 0.039 & 0.039 & 0.038 & 0.042 & 0.042 & 0.041 & 0.035 & 0.035 & 0.034 \\
\hline Any prelacteal feed & -0.030 & -0.031 & $-0.046^{\circ}$ & -0.043 & -0.043 & $-0.068^{* *}$ & -0.019 & -0.018 & -0.032 & 0.009 & 0.009 & 0.004 \\
\hline & 0.025 & 0.025 & 0.025 & 0.027 & 0.027 & 0.026 & 0.028 & 0.028 & 0.028 & 0.023 & 0.023 & 0.023 \\
\hline Breastfed within 1 hour of birth & $0.052 *$ & $0.051 *$ & $0.057^{* *}$ & $0.049 *$ & $0.049 *$ & $0.052 *$ & 0.034 & 0.035 & 0.038 & -0.020 & -0.021 & -0.013 \\
\hline & 0.022 & 0.022 & 0.022 & 0.023 & 0.023 & 0.023 & 0.025 & 0.025 & 0.024 & 0.020 & 0.020 & 0.020 \\
\hline Had diarrhoea in the last 2 weeks & -0.023 & -0.022 & -0.023 & $0.094^{* * *}$ & $0.095^{* * *}$ & $0.095^{* * *}$ & 0.085 ** & $0.086^{* *}$ & $0.088^{* *}$ & 0.017 & 0.018 & 0.020 \\
\hline & 0.026 & 0.026 & 0.026 & 0.027 & 0.027 & 0.026 & 0.028 & 0.028 & 0.028 & 0.024 & 0.024 & 0.024 \\
\hline Birth order & $0.069^{* * *}$ & $0.068^{* * *}$ & $0.138^{* * *}$ & $0.065^{* * *}$ & $0.064^{* * *}$ & $0.141^{* * *}$ & 0.028 ** & $0.028^{* *}$ & $0.063^{* * *}$ & 0.004 & 0.004 & $0.032^{* * *}$ \\
\hline & 0.010 & 0.009 & 0.009 & 0.010 & 0.010 & 0.009 & 0.010 & 0.010 & 0.010 & 0.009 & 0.009 & 0.008 \\
\hline Birth interval & $-0.002 * * *$ & $-0.002^{* * *}$ & $*-0.002 * * *$ & $-0.003^{* * * *}$ & $-0.003^{* * *}$ & $-0.003 * * *$ & $-0.002 * * *$ & $-0.002 * * *$ & $*-0.002 * * *$ & 0.000 & 0.000 & 0.000 \\
\hline & 0.000 & 0.000 & 0.000 & 0.000 & 0.000 & 0.000 & 0.000 & 0.000 & 0.000 & 0.000 & 0.000 & 0.000 \\
\hline & 0.025 & 0.025 & & 0.026 & 0.026 & & 0.028 & 0.028 & & 0.024 & 0.024 & \\
\hline Higher & $-0.484^{* * *}$ & $-0.485 * * *$ & & $-0.538^{* * * *}$ & $-0.538^{* * *}$ & & $-0.168^{* * *}$ & $-0.168^{* * *}$ & & $-0.220^{* * *}$ & * $-0.222 * * *$ & \\
\hline & 0.043 & 0.043 & & 0.046 & 0.046 & & 0.048 & 0.048 & & 0.037 & 0.037 & \\
\hline $\mathrm{HH}$ size & $-0.015^{* * * *}$ & $-0.015 * * *$ & * $-0.027 * * *$ & $-0.013 * *$ & $-0.013^{* *}$ & $-0.028 * * *$ & -0.007 & -0.007 & $-0.014 * * *$ & $0.009 *$ & $0.009 *$ & 0.003 \\
\hline & 0.004 & 0.004 & 0.004 & 0.004 & 0.004 & 0.004 & 0.004 & 0.004 & 0.004 & 0.004 & 0.004 & 0.003 \\
\hline Female head of $\mathrm{HH}$ & -0.003 & -0.004 & 0.000 & -0.024 & -0.024 & -0.014 & $-0.060^{\circ}$ & $-0.059^{\circ}$ & -0.051 & -0.030 & -0.030 & -0.034 \\
\hline & 0.029 & 0.029 & 0.028 & 0.030 & 0.030 & 0.029 & 0.032 & 0.032 & 0.032 & 0.026 & 0.026 & 0.026 \\
\hline Number of children under 5 in $\mathrm{HH}$ & $0.084^{* * *}$ & $0.084^{* * *}$ & $0.100^{* * *}$ & $0.067^{* * *}$ & $0.067^{* * *}$ & $0.081^{* * *}$ & 0.013 & 0.014 & 0.017 & 0.005 & 0.006 & 0.010 \\
\hline & 0.013 & 0.013 & 0.013 & 0.014 & 0.014 & 0.014 & 0.015 & 0.015 & 0.015 & 0.012 & 0.012 & 0.012 \\
\hline Scheduled caste/tribe & $0.125^{* * *}$ & $0.121^{* * *}$ & & $0.154^{* * *}$ & $0.151 * * *$ & & $0.087^{* * *}$ & $0.084^{* * *}$ & & $0.214^{* * *}$ & 0.212 *** & \\
\hline & 0.021 & 0.021 & & 0.021 & 0.021 & & 0.023 & 0.023 & & 0.019 & 0.019 & \\
\hline Wealth quintile (comp. to lowest) & & & & & & & & & & & & \\
\hline Lower middle & $-0.136 * * *$ & $-0.136^{* * *}$ & & $-0.233^{* * *}$ & $-0.233^{* * *}$ & & $-0.180^{* * *}$ & $-0.181^{* * *}$ & & -0.017 & -0.017 & \\
\hline & 0.027 & 0.027 & & 0.028 & 0.028 & & 0.030 & 0.030 & & 0.026 & 0.026 & \\
\hline Middle & $-0.309 * * *$ & $-0.306^{* * *}$ & & $-0.416^{* * *}$ & $-0.414^{* * *}$ & & $-0.273^{* * * *}$ & $-0.271^{* * *}$ & & $-0.061 *$ & $-0.061 *$ & \\
\hline & 0.032 & 0.032 & & 0.033 & 0.033 & & 0.036 & 0.036 & & 0.030 & 0.030 & \\
\hline Upper middle & $-0.490^{* * *}$ & $-0.485 * * *$ & & $-0.620 * * *$ & $-0.615 * * *$ & & $-0.400 * * *$ & $-0.394^{* * *}$ & & $-0.069^{\circ}$ & $-0.067^{\circ}$ & \\
\hline & 0.040 & 0.040 & & 0.041 & 0.041 & & 0.044 & 0.044 & & 0.036 & 0.036 & \\
\hline Highest & $-0.671^{* * *}$ & $-0.662 * * *$ & & $-0.825 * * *$ & $-0.819^{* * *}$ & & $-0.475 * * *$ & $-0.468^{* * *}$ & & $-0.177^{* * *}$ & $-0.173^{* * *}$ & \\
\hline & 0.050 & 0.050 & & 0.053 & 0.053 & & 0.055 & 0.055 & & 0.044 & 0.044 & \\
\hline Sanitation & & & & & & & & & & & & \\
\hline Private improved toilet & -0.026 & -0.029 & $-0.289 * * *$ & $-0.047^{\circ}$ & $-0.050^{\circ}$ & $-0.358 * * *$ & -0.033 & -0.037 & $-0.204 * * *$ & -0.084 **: & $-0.085^{* * *}$ & $-0.172^{* * * *}$ \\
\hline & 0.025 & 0.025 & 0.021 & 0.026 & 0.026 & 0.022 & 0.028 & 0.028 & 0.024 & 0.023 & 0.023 & 0.019 \\
\hline District toilet prevalence & -0.115 & $-0.139^{\circ}$ & $-0.372 * * *$ & $-0.270 * * *$ & $-0.282 * * *$ & $-0.589 * * *$ & -0.127 & $-0.140^{\circ}$ & $-0.295^{* * *}$ & $-0.127 \circ$ & $-0.135 *$ & $-0.213^{* *}$ \\
\hline & 0.074 & 0.073 & 0.071 & 0.077 & $\begin{array}{ll}0.078 \\
\end{array}$ & 0.074 & 0.081 & 0.082 & 0.079 & 0.068 & 0.068 & 0.066 \\
\hline
\end{tabular}

${ }^{* * *} p<0.001{ }^{* *} p<0.01{ }^{*} p<.05^{\circ} p<0.1$. All regressions were estimated using multilevel logit regressions, with state as the grouping variable. The numbers next to the variables are coefficients, below are standard errors. The $\mathrm{N}$ for all regressions is $57,021$. 
Table 4. The effects of IYCF on 4 and 5-month-old Indian children

\begin{tabular}{|c|c|c|c|c|}
\hline & Stunted & Underweight & Wasted & Anaemic \\
\hline \multicolumn{5}{|l|}{ Infant \& young child feeding } \\
\hline \multirow[t]{2}{*}{ Weaned (eating non-liquid food) } & -0.076 & $-0.119 *$ & -0.001 & 0.019 \\
\hline & 0.065 & 0.059 & 0.052 & 0.047 \\
\hline \multirow[t]{2}{*}{ Breastfeeding } & -0.119 & -0.108 & -0.088 & 0.056 \\
\hline & 0.095 & 0.108 & 0.157 & 0.093 \\
\hline \multicolumn{5}{|l|}{ Child characteristics } \\
\hline \multirow[t]{2}{*}{ Female child } & $-0.145 * * *$ & $-0.055 *$ & -0.020 & -0.020 \\
\hline & 0.030 & 0.026 & 0.039 & 0.034 \\
\hline \multirow[t]{2}{*}{5 months old (as opposed to 4 ) } & 0.006 & 0.035 & 0.012 & -0.063 \\
\hline & 0.042 & 0.043 & 0.053 & 0.034 \\
\hline \multirow[t]{2}{*}{ Small birth size } & $0.249 * * *$ & $0.367 * * *$ & $0.132 * *$ & -0.010 \\
\hline & 0.071 & 0.058 & 0.050 & 0.047 \\
\hline \multirow[t]{2}{*}{ Preterm } & $0.163 * *$ & $0.183 * *$ & -0.094 & 0.079 \\
\hline & 0.057 & 0.070 & 0.055 & 0.076 \\
\hline \multirow[t]{2}{*}{ Any prelacteal feed } & -0.018 & -0.052 & -0.063 & 0.063 \\
\hline & 0.028 & 0.034 & 0.042 & 0.043 \\
\hline \multirow[t]{2}{*}{ Breastfed within 1 hour of birth } & 0.052 & 0.038 & 0.002 & -0.010 \\
\hline & 0.045 & 0.037 & 0.033 & 0.030 \\
\hline Had diarrhoea in the last 2 weeks & $-0.147 *$ & -0.023 & 0.017 & -0.005 \\
\hline & 0.058 & 0.032 & 0.041 & 0.056 \\
\hline Birth order & -0.005 & 0.003 & 0.006 & 0.031 \\
\hline & 0.022 & 0.015 & 0.021 & 0.019 \\
\hline Birth interval & -0.001 & $-0.003 * * *$ & 0.000 & -0.001 \\
\hline & 0.001 & 0.001 & 0.001 & 0.001 \\
\hline Household characteristics & & & & \\
\hline Mother's age at birth & -0.006 & 0.003 & 0.005 & $-0.020 * * *$ \\
\hline & 0.006 & 0.004 & 0.006 & 0.004 \\
\hline Mother undernourished & 0.042 & $0.268 * * *$ & $0.175^{* * *}$ & $0.191 * * *$ \\
\hline & 0.070 & 0.072 & 0.043 & 0.036 \\
\hline Mother's education (comp. to none) & 0.000 & 0.000 & 0.000 & 0.000 \\
\hline Primary & -0.074 & 0.009 & 0.020 & -0.057 \\
\hline & 0.065 & 0.047 & 0.054 & 0.047 \\
\hline Secondary & $-0.125 *$ & -0.037 & -0.053 & $-0.155 * * *$ \\
\hline & 0.052 & 0.049 & 0.052 & 0.035 \\
\hline Higher & -0.199 & -0.050 & 0.083 & -0.101 \\
\hline & 0.133 & 0.094 & 0.055 & 0.054 \\
\hline HH size & -0.003 & 0.001 & 0.000 & 0.011 \\
\hline & 0.008 & 0.006 & 0.005 & 0.007 \\
\hline Female head of $\mathrm{HH}$ & 0.023 & 0.016 & 0.075 & -0.037 \\
\hline & 0.060 & 0.050 & 0.066 & 0.051 \\
\hline Number of children under 5 in $\mathrm{HH}$ & -0.009 & 0.009 & $0.056^{* *}$ & -0.008 \\
\hline & 0.029 & 0.017 & 0.020 & 0.024 \\
\hline Scheduled caste/tribe & 0.100 & $0.130 *$ & 0.017 & $0.154^{* *}$ \\
\hline & 0.055 & 0.056 & 0.053 & 0.050 \\
\hline Wealth quintile (comp. to lowest) & 0.000 & 0.000 & 0.000 & 0.000 \\
\hline Lower middle & $-0.148 * * *$ & $-0.225 * * *$ & -0.051 & -0.061 \\
\hline & 0.039 & 0.050 & 0.037 & 0.063 \\
\hline Middle & $-0.226^{* * *}$ & $-0.378^{* * *}$ & $-0.110 *$ & -0.062 \\
\hline & 0.056 & 0.082 & 0.044 & 0.094 \\
\hline Upper middle & $-0.271 * * *$ & $-0.354 * * *$ & -0.037 & $-0.173 *$ \\
\hline & 0.073 & 0.085 & 0.069 & 0.080 \\
\hline Highest & $-0.366 * * *$ & $-0.520 * * *$ & -0.097 & $-0.242 * *$ \\
\hline & 0.093 & 0.098 & 0.066 & 0.083 \\
\hline Sanitation & & & & \\
\hline Private improved toilet & -0.031 & -0.021 & 0.037 & 0.040 \\
\hline & 0.057 & 0.042 & 0.031 & 0.046 \\
\hline District toilet prevalence & -0.028 & -0.005 & -0.171 & 0.055 \\
\hline & 0.154 & 0.178 & 0.116 & 0.209 \\
\hline Communal characteristics & & & & \\
\hline Urban & $0.136^{* *}$ & $0.129 *$ & -0.001 & -0.015 \\
\hline & 0.044 & 0.055 & 0.041 & 0.037 \\
\hline Region (comp. to Southern) & & & & \\
\hline Northeastern & $-0.351 * * *$ & $-0.541 * * *$ & $-0.536^{* * *}$ & -0.173 \\
\hline & 0.104 & 0.133 & 0.134 & 0.179 \\
\hline Northern & -0.142 & 0.054 & -0.046 & $0.416 *$ \\
\hline & 0.129 & 0.089 & 0.102 & 0.184 \\
\hline Eastern & -0.021 & 0.147 & -0.020 & 0.083 \\
\hline & 0.120 & 0.100 & 0.101 & 0.194 \\
\hline Central & 0.039 & $0.232 *$ & -0.047 & 0.179 \\
\hline & 0.139 & 0.092 & 0.102 & 0.150 \\
\hline Western & -0.045 & 0.112 & 0.138 & 0.006 \\
\hline & 0.124 & 0.073 & 0.127 & 0.154 \\
\hline
\end{tabular}

${ }^{* * *} p<0.001{ }^{* *} p<0.01{ }^{*} p<.05^{\circ} p<0.1$

The numbers next to the variables are coefficients, below are standard errors. The $\mathrm{N}$ for all regressions was 6,570. 
Table 8. Effects of ICDS on children's feeding habits and nutritional outcomes (PSM nearest-neighbour approach)

\begin{tabular}{|c|c|c|c|c|c|c|c|}
\hline \multirow[t]{2}{*}{ ICDS } & \multirow[b]{2}{*}{ Weaned } & \multirow[b]{2}{*}{$\begin{array}{c}\text { Satisf. diet. } \\
\text { diversity }\end{array}$} & \multirow[b]{2}{*}{ Any ASF } & \multirow[b]{2}{*}{ Stunted } & \multirow[b]{2}{*}{ Underweight } & \multirow[b]{2}{*}{ Wasted } & \multirow[b]{2}{*}{ Anaemic } \\
\hline & & & & & & & \\
\hline \multirow[t]{2}{*}{ Food at least weekly } & & $0.025 *$ & -0.001 & 0.019 & -0.002 & $0.027 *$ & 0.017 \\
\hline & & 0.013 & 0.015 & 0.016 & 0.015 & 0.014 & 0.016 \\
\hline \multirow[t]{2}{*}{ Health check-up at least monthly } & $-0.023 * *$ & $0.026 * *$ & 0.016 & 0.008 & 0.002 & -0.006 & $0.026 * *$ \\
\hline & 0.009 & 0.009 & 0.011 & 0.011 & 0.010 & 0.009 & 0.011 \\
\hline \multirow[t]{2}{*}{ Weight/height check at least monthly } & 0.006 & -0.002 & -0.001 & 0.013 & -0.003 & 0.003 & 0.009 \\
\hline & 0.008 & 0.008 & 0.001 & 0.001 & 0.001 & 0.009 & 0.010 \\
\hline \multirow[t]{2}{*}{ Regular ICDS preschool attendance } & $-0.021 * *$ & $0.028 * * *$ & $0.028 * * *$ & 0.007 & 0.004 & 0.004 & 0.000 \\
\hline & 0.007 & 0.007 & 0.009 & 0.009 & 0.009 & 0.008 & 0.009 \\
\hline
\end{tabular}

${ }^{* * *} p<0.001^{* *} p<0.01^{*} p<.05^{\circ} p<0.1$ 
Figures

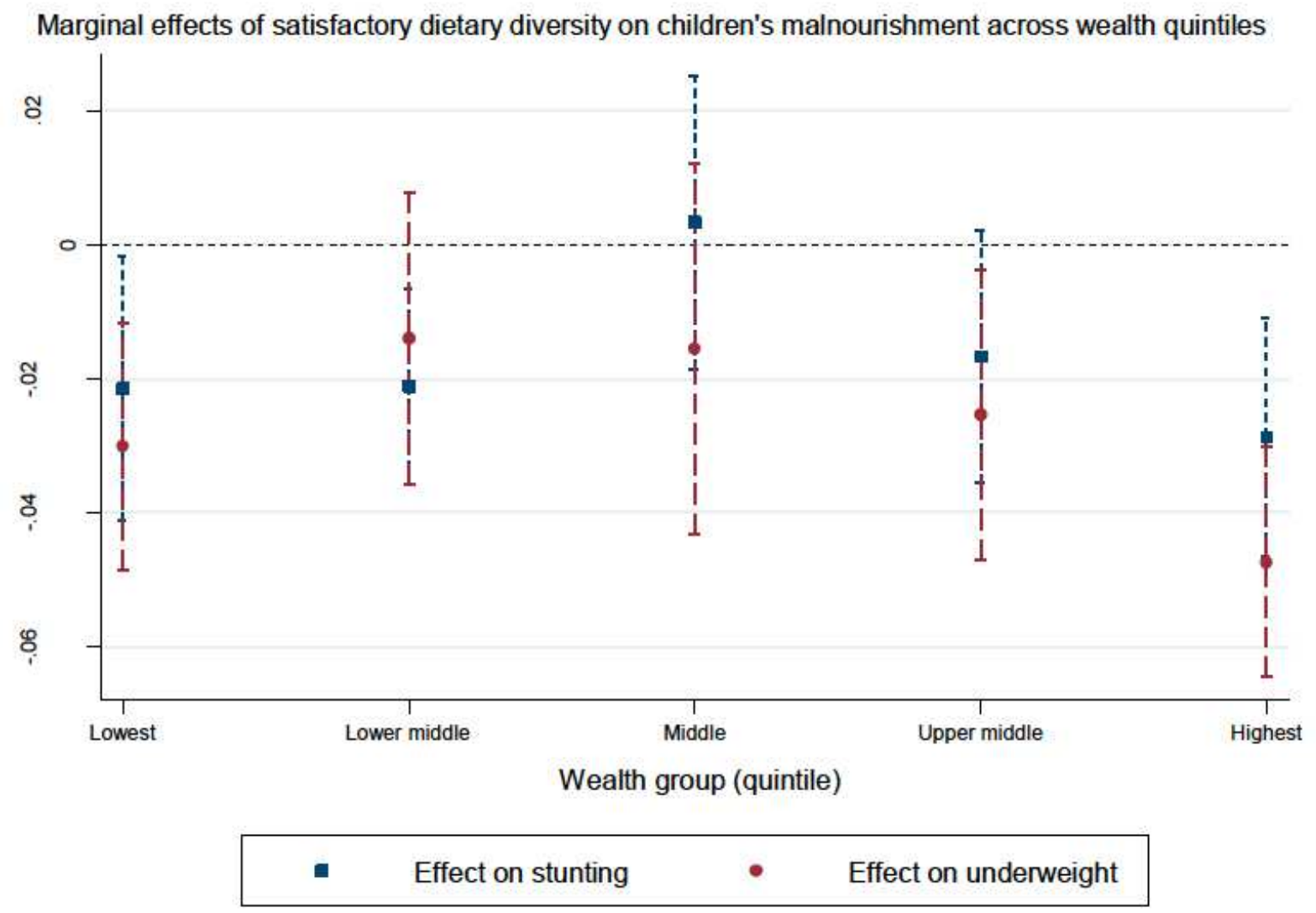

Marginal effects calculated from regressions akin to models (1) and (4) in Table 2, with the addition of an interaction term between satisfactory dietary diversity and households' wealth group

\section{Figure 1}

The effects of minimum dietary diversity on children's stunting and underweight across different wealth groups 


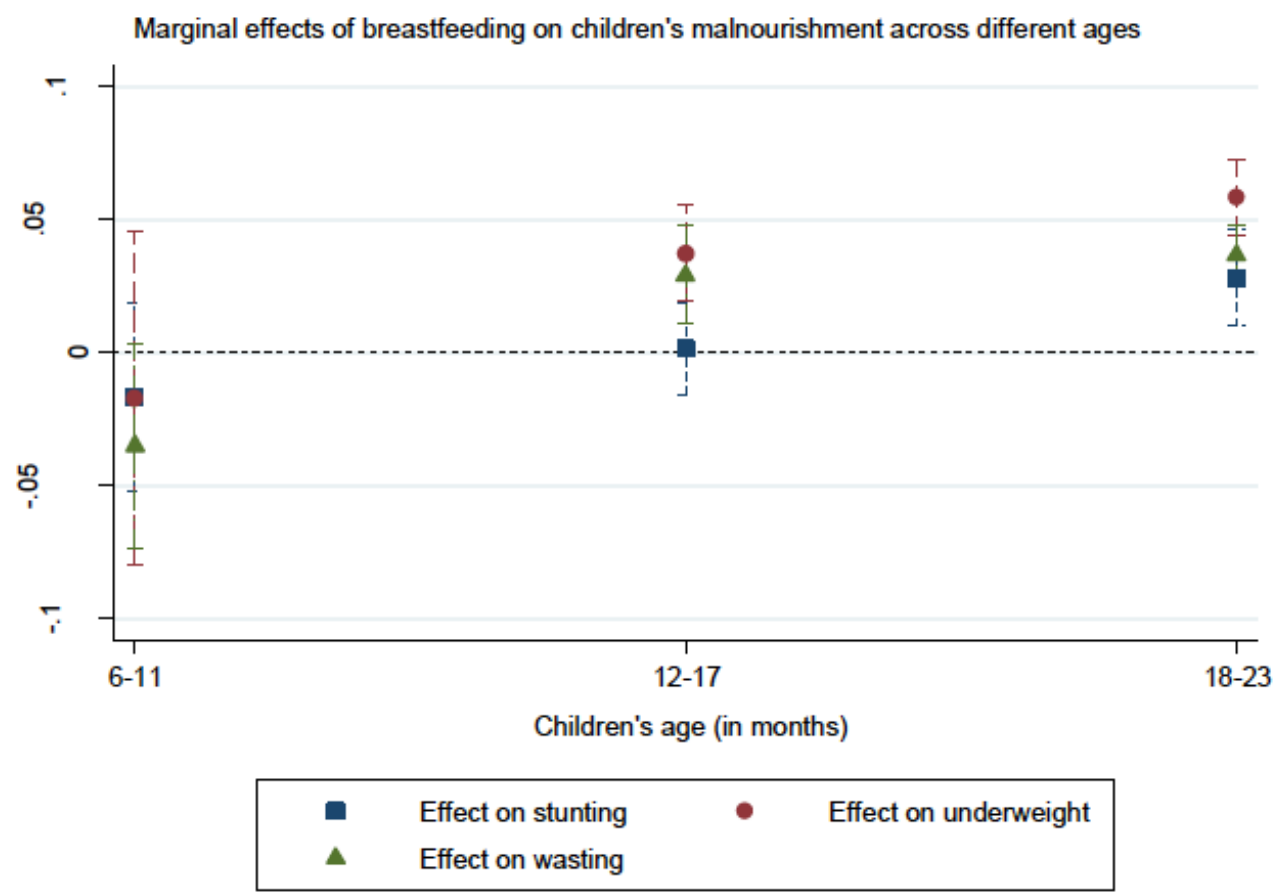

Marginal effects calculated from regressions akin to models (1), (4), and (7) in Table 2, with the addition of an interaction term between breastfeeding and children's age group

\section{Figure 2}

The effects of breastfeeding on children's nutritional outcomes by age groups

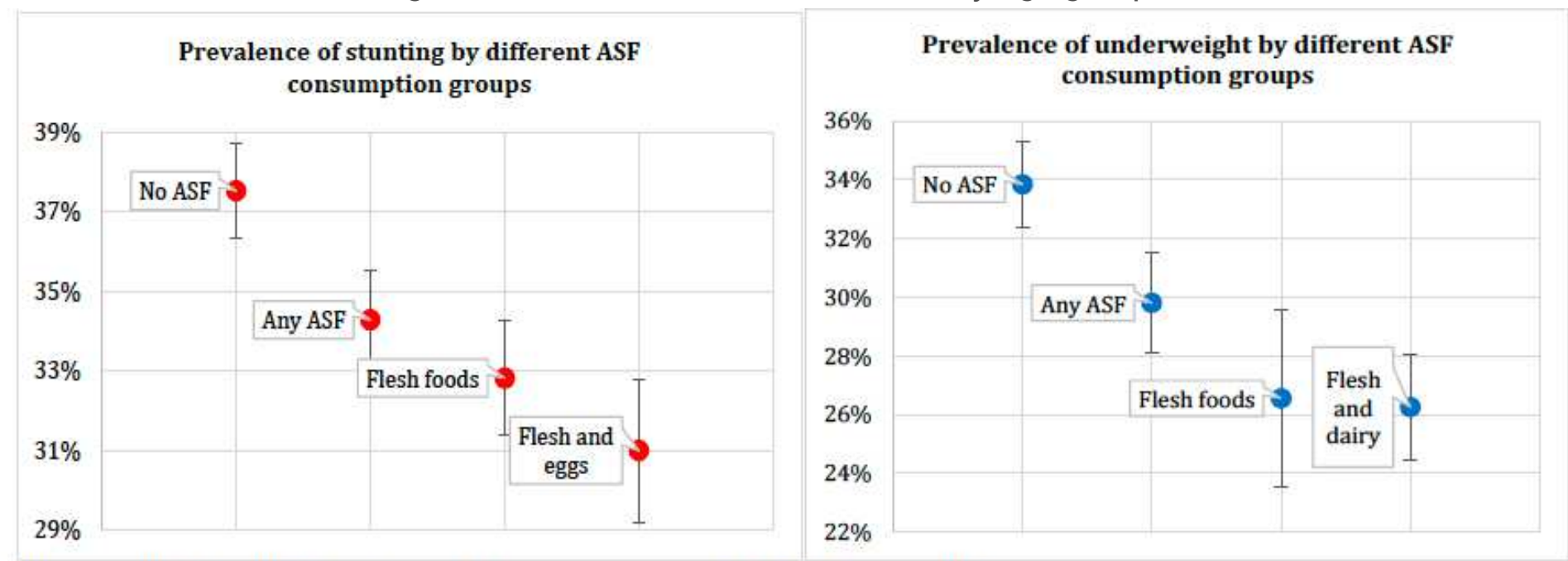

Figures display effects estimated from regressions (1) an (2) in Table 6.

\section{Figure 3}

$(a, b)$. Effects of different animal-source foods on children's nutritional outcomes 


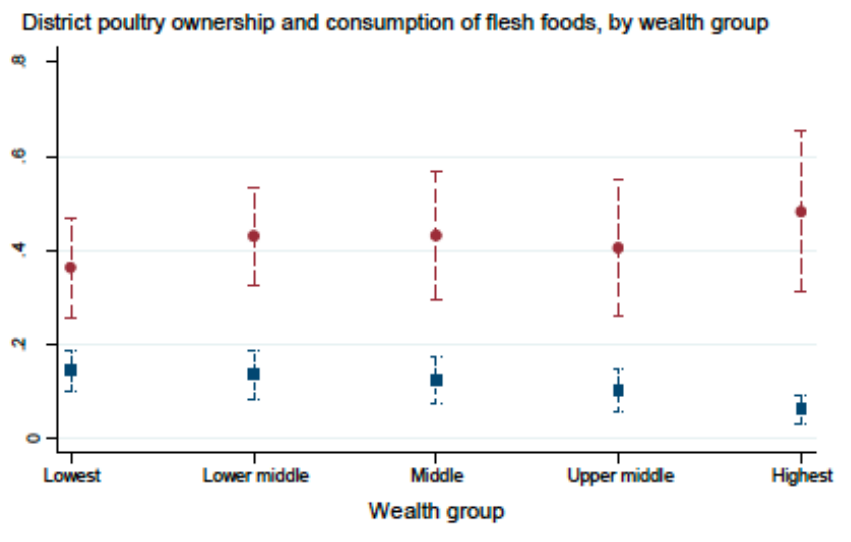

- Lowest poultry ownership $\quad \bullet \quad$ Highest poultry ownership

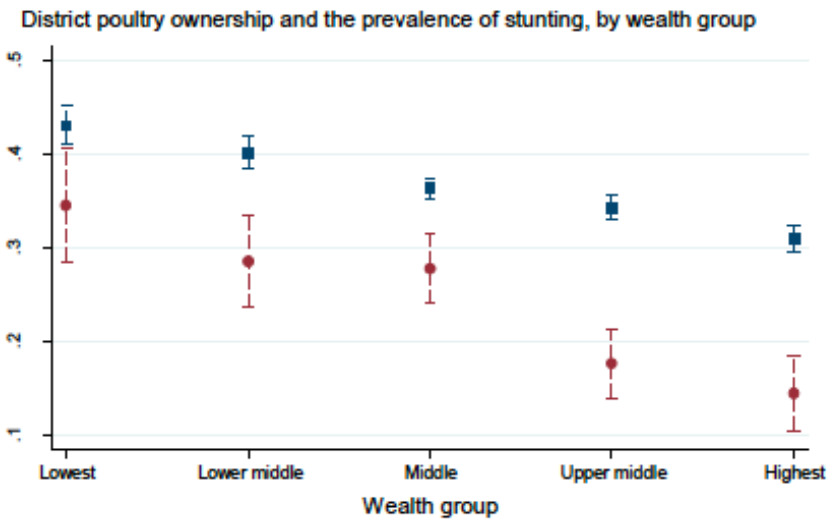

- Lowest poultry ownership @ Highest poultry ownership

Marginal effects from regressions akin to (9) and (11) in Table 7, with the addition of an interaction term between poultry ownership and households' wealth group.

\section{Figure 4}

The effects of district poultry ownership on children eating flesh foods 